\title{
Assessment of Human-Structure Interaction on a Lively Lightweight GFRP
}

\section{Footbridge}

Ehsan Ahmadi ${ }^{1}$, Colin Caprani ${ }^{1 *}$, Stana Živanović ${ }^{2}$, Amin Heidarpour $^{1}$

${ }^{1}$ Dept. of Civil Engineering, Monash University, Australia

${ }^{2}$ School of Engineering, University of Warwick, UK

* Corresponding Author

\section{Abstract}

Human activities and occupancy can induce excessive structural vibrations. Human-structure interaction (HSI) can significantly affect responses. However, this phenomenon is not accounted for in many design guidelines due to lack of experimental studies. Concurrently, there is increasing application of lightweight high-strength materials such as glass fibre reinforced polymer (GFRP). The vibration sensitivity of such structures is not yet well known, despite the expectation that it could be important due to high human-to-structure mass ratio. This paper examines the effect of HSI on the vibration response prediction of a lively lightweight GFRP footbridge, and it compares the results to those from a heavy concretecomposite footbridge. An extensive ensemble of test trials was conducted, accompanied by a survey on vibration perception by the walkers. The influence of HSI on the lightweight bridge vibration response is quantified. It is found that the non-interacting moving force models produce poor predictions, especially for the GFRP bridge. It is also found that vibration of the bridge had a strong influence on walking force, and to a lesser extent on the dynamics of the human-structure system. Finally, it is found that the response factor of about 2 is appropriate for determining the vibration tolerance level by walkers.

\section{Keywords}

Footbridge; vibration; GFRP; human-structure interaction; vibration perception; force models. 
This paper has been published under the following reference: Ahmadi, E., Caprani, C., Zivanovic, S. and Heidarpour, A. Assessment of Human-Structure Interaction on a Lively Lightweight GFRP Footbridge. Engineering Structures. Vol. 199. Nov 2019. DOI: https://doi.org/10.1016/i.engstruct.2019.109687

\section{Introduction}

\subsection{Background}

The vibration performance of many modern footbridges under human walking is a vital serviceability consideration. Inaccurate vibration response predictions at the design stage can result in the design of structures which exhibit excessive vibrations during their service. On the other hand, overly-conservative models of vibration response incur additional unnecessary costs. Concurrently, the application of high-strength lightweight materials such as fibrereinforced polymer (FRP) is increasing in the building and civil construction industries. However, so far there are limited studies on the vibration performance of such structures [1].

Živanović et al. [2] compared the vibration performance of lightweight FRP bridges (i.e. Aberfeldy and EMPA bridges) with non-FRP (heavier) bridges (i.e. Podgorica, Sheffield, and Warwick Bridges). It was concluded that the relatively lower modal mass of the FRP bridges results in increased liveliness (i.e., accelerance) compared to the non-FRP bridges. He and Xie [3] studied the dynamic properties of a lightweight steel-concrete composite bridge under walking people, and found that the pedestrian-to-bridge mass ratio plays a key role in the dynamic properties of the human-bridge system. From the results of these studies, it can be seen that neglecting the effect of human-structure interaction (HSI), as is done in many current guidelines, will lead to inaccurate vibration prediction for lively lightweight structures [4]. In a unique series of research works, Dey and his colleagues ([5], [6], [7]) studied dynamic performance of lightweight aluminium footbridges and accuracy of current pedestrian load models. They reported that these footbridges tend to be lively due to their low damping and light weight, and more detailed walking load models are also required for accurate vibration response estimation of lightweight structures. Particularly in the case of near-resonant, the footbridge vibration was seen to be overestimated. However, contribution of HSI was not clearly specified and quantified. 
This paper has been published under the following reference: Ahmadi, E., Caprani, C., Zivanovic, S. and Heidarpour, A. Assessment of Human-Structure Interaction on a Lively Lightweight GFRP Footbridge. Engineering Structures. Vol. 199. Nov 2019. DOI:

https://doi.org/10.1016/i.engstruct.2019.109687

In the context of the structural vibration serviceability, HSI is defined as the mutual dynamic

effects of the human and the structure on one another. HSI occurs as a feedback loop when the structure and human are in contact. Walking causes the vibration which is perceived, in turn altering the walking characteristics and hence the subsequent vibration. HSI thus has two parts: (1) Structure-to-Human Interaction (S2HI): the effects of the structural vibration on the human walking forces which are also referred to as ground reaction forces (GRFs); (2) Human-toStructure Interaction (H2SI): the influences of the human body on the dynamic properties of the human-structure system. Vibration in the vertical direction is the focus of this study.

\subsection{Previous studies}

For current structural vibration response predictions in practice, the imparted human force is often modelled as a continuous constant-velocity moving force (e.g. OHBDC [8], U.K. National Annex to Eurocode 1 [9], ISO-10137 [10], Eurocode 5 [11], Setra [12], and HIVOSS [13]). This time-varying force is typically represented using a Fourier series representation:

$$
G(t)=W_{p} \sum_{k=0}^{N} D L F_{k} \cos \left(2 \pi k f_{p} t+\varphi_{k}\right)
$$

where $W_{p}=m_{p} g ; m_{p}$ is the pedestrian mass; $g$ is the acceleration due to gravity; $f_{p}$ is the pacing frequency; and $D L F_{k}$ is the dynamic load factor for the $k$ th harmonic. The phase angle of the $k$ th harmonic is denoted by $\varphi_{k}$, and $N$ represents total number of harmonics considered. In this representation, the harmonic $k=0$ corresponds to the static pedestrian weight, and so $\varphi_{0}=0$ to give $D L F_{0}=1$. Clearly, the DLFs are essential to this representation, and these are usually based upon measured walking forces on rigid surfaces ([14], [15], [16], [17]). Both the moving force model using equation (1) and the rigid surface-based DLFs do not allow for consideration of HSI. Thus, for structures where HSI significantly influences the vibration response (such as lightweight footbridges), this non-interacting force model will lead to inaccurate response predictions. 
This paper has been published under the following reference: Ahmadi, E., Caprani, C., Zivanovic, S. and Heidarpour, A. Assessment of Human-Structure Interaction on a Lively Lightweight GFRP Footbridge. Engineering Structures. Vol. 199. Nov 2019. DOI:

https://doi.org/10.1016/i.engstruct.2019.109687

The importance of HSI on the accurate prediction of vibration response has attracted increasing attention from researchers in the last few years. Shahabpoor et al. [4] comprehensively surveyed the literature on HSI in the vertical direction. For the effect of the structural vibration on the human (i.e. S2HI), a reduction in the magnitude of walking force due to the vibrating surface has been reported by several authors. Ohlsson [18] found such a reduction when walking close to the frequency of the structure (i.e. "resonant walking”). Likewise, Baumann and Bachmann [19] reported a 10\% reduction (approximately) in DLFs for two test subjects walking on a vibrating surface. Pimentel [20] matched measured vibration responses with those simulated from a moving force model, concluding that it is necessary to have reductions in the first and second DLFs. Dang and Živanović [21] used a stationary instrumented treadmill on a lively bridge, reporting a considerable drop (up to 53\%) in DLFs around the vibration frequency. Ahmadi et al. ([22], [23]) conducted numerous walking trials on two lively footbridges, measuring walking forces on both rigid and bridge surfaces. It was found that the vibrating surface causes a reduction in the DLF of the walking force harmonic of frequency close to the vibration frequency. Specifically, for the University of Warwick Bridge (a $2.4 \mathrm{~Hz}$ $16 \mathrm{t}$ bridge) a significant drop (up to 10\%) in the mean of first DLF was found [24], while for the Monash University bridge (a $5.6 \mathrm{~Hz} 900 \mathrm{~kg}$ bridge), a considerable drop (up to 30\%) in the mean of the third harmonic DLF was observed [22].

HSI also includes the effects of humans on the dynamic properties of the coupled humanstructure systems (H2SI) [4]. The effects of a stationary person on the mass, damping, and frequency of the structure are quite well known [17], [4], [25], [26]. Furthermore, walking people can also considerably increase the damping and reduce the frequency of the coupled system [18], [27], [28], [29], [30], [31]. For example, Kasperski [32] concluded that the damping added to the bridge by a pedestrian can be as high as $13 \%$. More recently, Ahmadi et al. [24] designed and adopted a novel experimental-numerical programme to quantify the 
This paper has been published under the following reference: Ahmadi, E., Caprani, C., Zivanovic, S. and Heidarpour, A. Assessment of Human-Structure Interaction on a Lively Lightweight GFRP Footbridge. Engineering Structures. Vol. 199. Nov 2019. DOI:

https://doi.org/10.1016/i.engstruct.2019.109687

effects of HSI (including H2SI) on the response of the University of Warwick footbridge on which human-to-structure mass was up to $0.7 \%$ [24]. Considering the increased mass ratios on lightweight structures, it is postulated that the effect of H2SI (and S2HI) could be even greater on these structures, such as GFRP footbridges.

\subsection{Contribution}

Despite the previous work surveyed above, the influence of HSI on the vibration response of lively lightweight structures is not yet quantified fully. Quantification of HSI is important for critical evaluation and upgrading of moving force models. Furthermore, it also could provide insight into relationship between the HSI and the human-to-structure mass ratio. Consequently, the specific aims of this work are to:

1. Aim 1: evaluate the accuracy of current non-interacting force models for a lightweight GFRP bridge (the Monash Bridge), and a comparatively heavier bridge (the Warwick Bridge).

2. Aim 2: quantify the influence of HSI on the vibration response of the lightweight GFRP bridge using an experimental-numerical framework.

3. Aim 3: ascertain whether HSI influences the vibration response of light and heavy structures differently for structures considered to be lively by test participants (e.g. the Monash and Warwick bridges used in this study).

To address these aims, we first describe an experimental-numerical framework which provides the data required for the analysis (Section 2). The main experimental setup and walking trials are explained in Section 2; a preparatory shaker experiment for quantification of walking force measurements and bridge numerical modelling errors and the results are presented in Section 3; and the results of the walking tests experiments are given in Section 4. The best-practice simulation of vibration response using moving force models is described in Section 5. Finally, Section 6 evaluates and discusses the results from the previous sections to address the three aims of the work. 
This paper has been published under the following reference: Ahmadi, E., Caprani, C., Zivanovic, S. and Heidarpour, A. Assessment of Human-Structure Interaction on a Lively Lightweight GFRP Footbridge. Engineering Structures. Vol. 199. Nov 2019. DOI:

https://doi.org/10.1016/i.engstruct.2019.109687

\section{Experimental Framework}

\subsection{Experimental-numerical programme}

The traditional view describes HSI as a change in the walking force or a change in the system's dynamic properties. However, this work uses the experimental-numerical programme proposed by Ahmadi et al. [24] for HSI classification. This new classification framework states that HSI can be described as a combination of the change in the walking force and the change in the system's dynamic properties. This approach is very beneficial for HSI quantification in terms of vibration response. Referring to Figure 1, three metrics are experimentally measured:

- $\quad$ GRFs on a rigid surface (RS), $G_{R S}(\mathrm{~b})$;

- GRFs on a vibrating bridge surface (BS), $G_{B S}(\mathrm{c})$, and;

- the bridge vibration response, $R_{M}(\mathrm{i})$.

Simulated vibration responses are found using the numerical bridge model (e) for three sources of walking force:

- Non-interacting force models, $G_{C M}(\mathrm{a})$, which leads to responses, $R_{C M}(\mathrm{f})$;

- GRFs measured on the rigid surface, $G_{R S}(\mathrm{~b})$, giving responses, $R_{R S}(\mathrm{~g})$, and;

- GRFs measured on the bridge surface, $G_{B S}(\mathrm{c})$, giving responses, $R_{B S}(\mathrm{~h})$.

With reference to the aims of this work, the experimental-numerical framework described allows the following determinations to be made:

- For Aim 1: Comparison of the non-interacting force model and the measured vibration responses, $R_{C M}$ and $R_{M}$, indicates the accuracy of current design guidelines in vibration response prediction for this lightweight structure.

- For Aim 2: Relative comparison of the vibration responses $R_{R S}$ and $R_{B S}$ demonstrates the influence of the vibrating bridge surface on the walking force (S2HI), since the numerical model remains unchanged; comparison of the bridge simulated vibration response, $R_{B S}$, to those measured from the footbridge, $R_{M}$, indicates the effect of human presence on the dynamic properties of the footbridge (H2SI). 
This paper has been published under the following reference: Ahmadi, E., Caprani, C., Zivanovic, S. and Heidarpour, A. Assessment of Human-Structure Interaction on a Lively Lightweight GFRP Footbridge. Engineering Structures. Vol. 199. Nov 2019. DOI:

https://doi.org/10.1016/i.engstruct.2019.109687

- For Aim 3: Comparison of the HSI quantification results of the lightweight GFRP Monash bridge and those obtained from the heavyweight Warwick footbridge [24] using the same experimental-numerical programme reveals potential differing effects of HSI on vibration response of the two types of bridges.

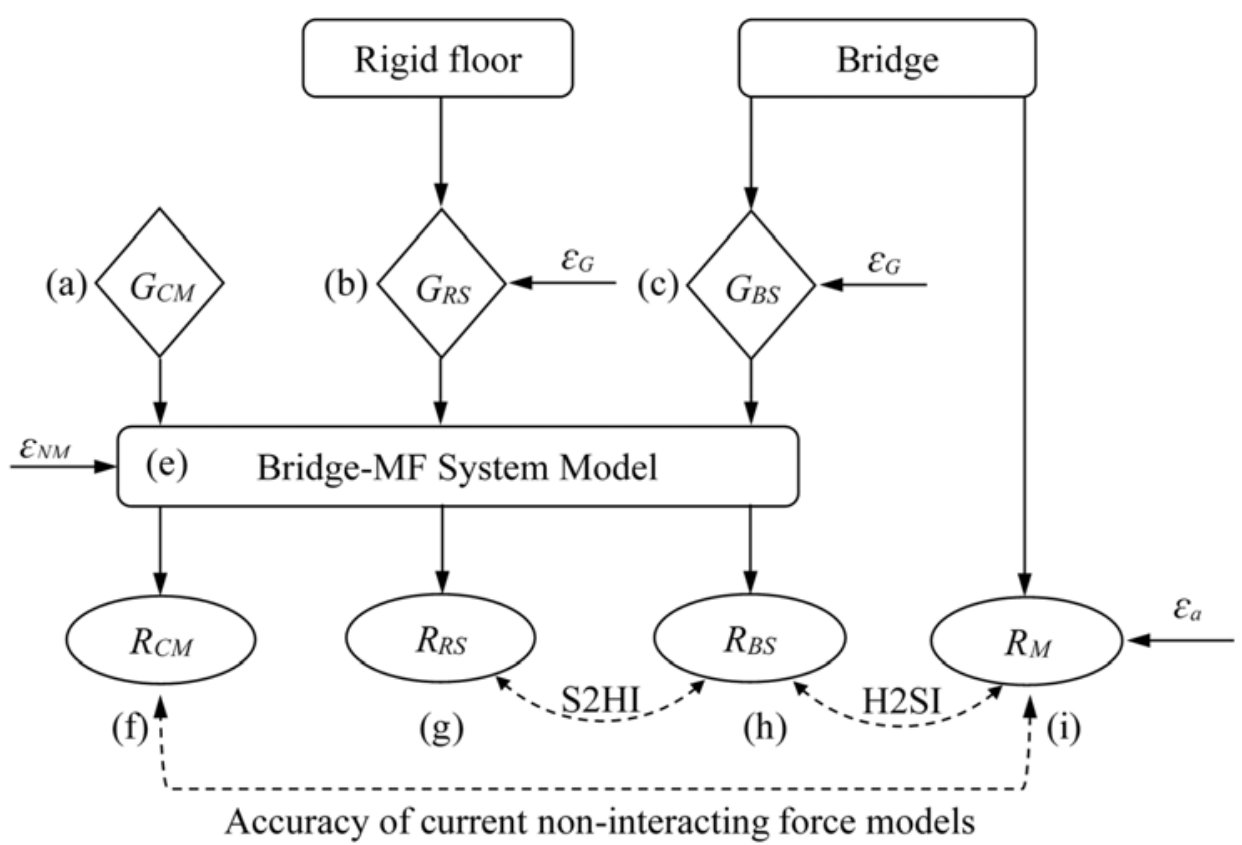

Figure 1. A schematic overview of the experimental-numerical programme used by Ahmadi et al. [24]. See the text for explanation of parts (a) to (i)- $\varepsilon_{a}$ is the error in the acceleration measurement.

The main sources of potential error in the experimental-numerical framework are the force measurement errors, $\varepsilon_{G}$, and the footbridge numerical model error, $\varepsilon_{N M}$. These two sources of error are quantified in Section 3.

\subsection{Human-induced vibration trials}

Walking trials were conducted on two bridges: a $16 \mathrm{~m}$ steel-concrete composite bridge at the University of Warwick, described in detail in [24]; and a $9 \mathrm{~m}$ lightweight GFRP laboratory footbridge in Monash University, Australia, described in detail in [22]. The results from the Warwick Bridge are used later as a comparison only, so we just describe the experiments on the Monash Bridge in more detail. 
This paper has been published under the following reference: Ahmadi, E., Caprani, C., Zivanovic, S. and Heidarpour, A. Assessment of Human-Structure Interaction on a Lively Lightweight GFRP Footbridge. Engineering Structures. Vol. 199. Nov 2019. DOI:

https://doi.org/10.1016/i.engstruct.2019.109687

All structural elements of the Monash Footbridge, shown in Figure 2a, are connected using epoxy bonding to provide full composite action. The transverse and longitudinal strength and stiffness of the footbridge are provided by bidirectional fibre orientations in the sandwich deck construction of flat sheets, box section, and I-beam girders [22]. A force plate was positioned on the surface of the footbridge, and so it was covered with a stiff foam (XPS) and thin wooden sheets (MDF) to provide a flat walking surface. This simply-supported covered footbridge has a natural frequency in the vertical direction of about $5.6 \mathrm{~Hz}$ that is in the range of the third harmonic of walking force. The covered bridge is 1.5 wide $\times 9 \mathrm{~m}$ long with total mass of $939 \mathrm{~kg}$.

Experiments involving people walking over the bridge were conducted for three pacing frequencies: (1) resonant walking with pacing frequency about $1.87 \mathrm{~Hz}(112$ beats/min of the metronome); (2) non-resonant walking with pacing frequency of $1.70 \mathrm{~Hz}$ (102 beats/min), and; (3) 'normal' walking using a pacing frequency self-determined as comfortable by test subjects. For each walking trial, test subjects walked a circuit including the bridge surface (BS), from $\mathrm{S} 1$ to $\mathrm{S} 2$, and the rigid surface (RS), from S3 to S4, as shown in Figure 2b. On both surfaces, the walking length was $13 \mathrm{~m}$. A metronome was used during resonant and non-resonant walking trials so that test subjects target the desired pacing frequency. After each bridge walk, test subjects were asked to classify their perception of the footbridge vibration.

Eighteen test subjects ( 9 male and 9 female) weighing from $444 \mathrm{~N}$ to $1489 \mathrm{~N}$ and $154 \mathrm{~cm}$ to $190 \mathrm{~cm}$ tall (Table 1) took part in the experiment. The human-to-bridge mass ratio, $\mu$, is also included in the table and used later to report the results for individual test subjects. Fifteen successful trials for each pacing frequency were collected. 
This paper has been published under the following reference: Ahmadi, E., Caprani, C., Zivanovic, S. and Heidarpour, A. Assessment of Human-Structure Interaction on a Lively Lightweight GFRP Footbridge. Engineering Structures. Vol. 199. Nov 2019. DOI:

\section{https://doi.org/10.1016/i.engstruct.2019.109687}

\subsection{Data acquisition}

To measure GRFs on bridge surface, $G_{B S}$, and the vibration response of the footbridge, $R_{M}$, a novel experimental setup was designed, shown in Figure 3. Three devices were used to measure GRFs: (1) A BERTEC FP4060-07 force plate [33] was placed on the footbridge surface approximately at mid-span; (2) Four C10 HBM load cells [34] supported the bridge, and; (3) A state-of-the-art in-shoe plantar pressure measurement system, the Tekscan F-scan ([35], [36], [37]), was used to measure GRFs on the bridge and rigid surfaces, $G_{B S}$ and $G_{R S}$. The vibration response of the footbridge was measured using two DYTRAN 3191A1 accelerometers placed at the two edges of the deck at mid-span, as shown in Figure 3. A more detailed description of the experimental setup and quality control procedures adopted are given by Ahmadi et al. [22].

(a)

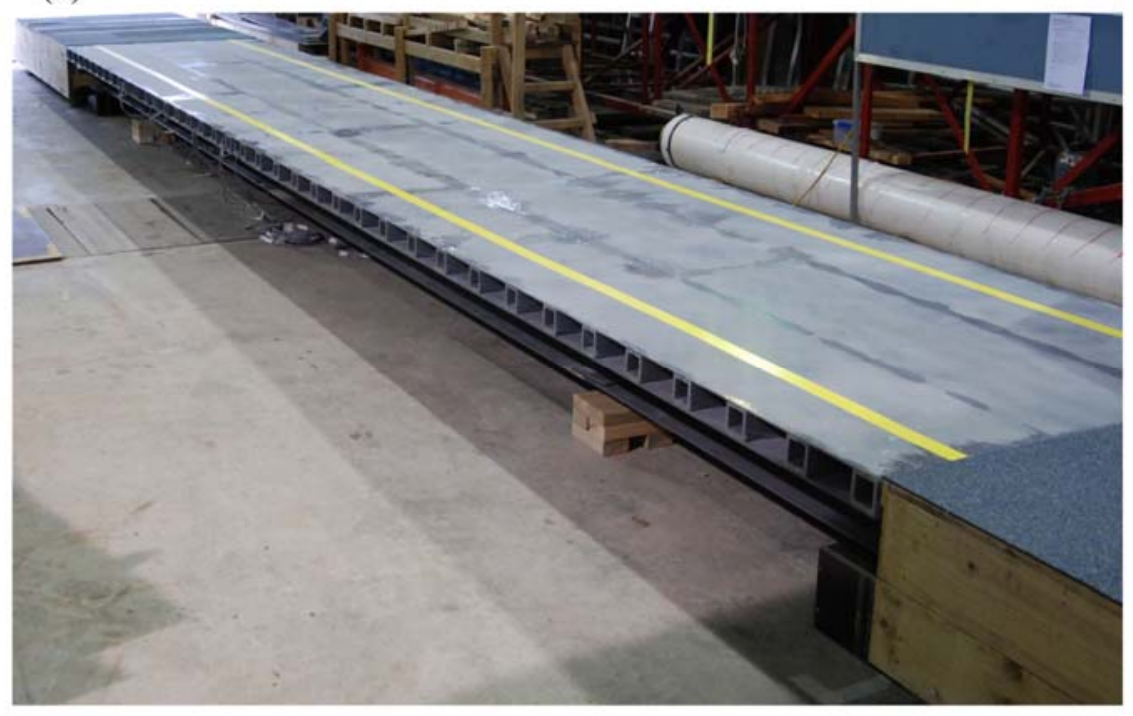

(b)

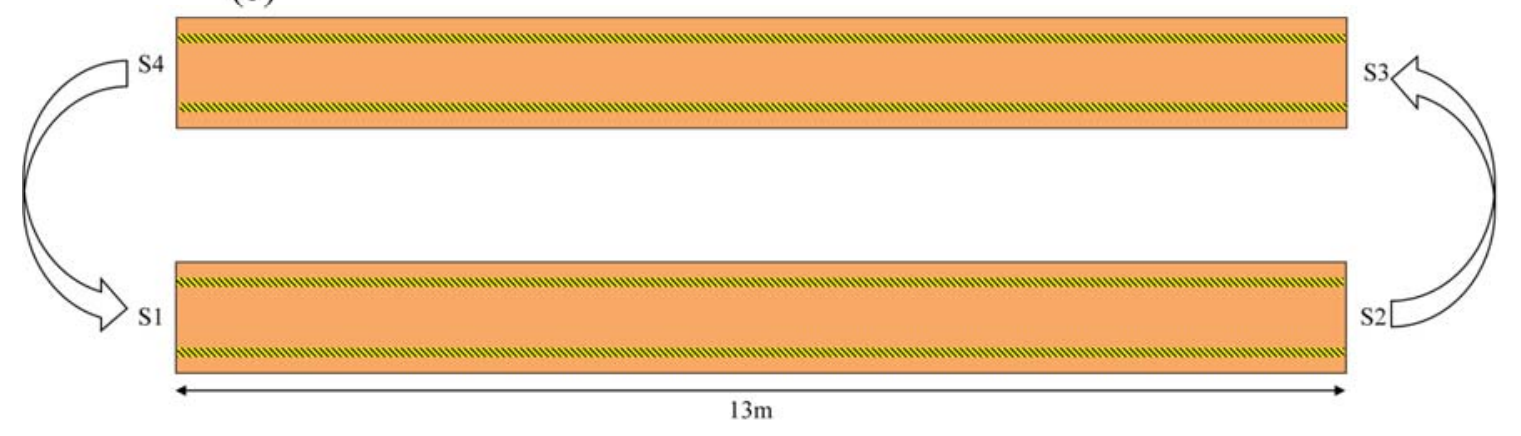

Figure 2. (a) Monash GFRP footbridge: uncovered footbridge structure with end walkways shown, and (b) walking path during each walking trial, S1-S2 is the bridge surface, and S3-S4 is the rigid surface. 
This paper has been published under the following reference: Ahmadi, E., Caprani, C., Zivanovic, S. and Heidarpour, A. Assessment of Human-Structure Interaction on a Lively Lightweight GFRP Footbridge. Engineering Structures. Vol. 199. Nov 2019. DOI:

https://doi.org/10.1016/i.engstruct.2019.109687

Table 1. Test subjects participated in this study ( $\mathrm{F}$ and $\mathrm{M}$ stand for female and male respectively).

Test Subject No. $\mu(\%)$ Height $(\mathrm{cm})$ Weight $(\mathrm{N})$

Gender

\begin{tabular}{|c|c|c|c|c|}
\hline 1 & 9.3 & 174 & 865 & M \\
\hline 2 & 7.8 & 172 & 718 & M \\
\hline 3 & 7.3 & 166 & 654 & M \\
\hline 4 & 4.8 & 154 & 444 & $\mathrm{~F}$ \\
\hline 5 & 7.4 & 181 & 678 & M \\
\hline 6 & 9.4 & 186 & 862 & M \\
\hline 7 & 7.8 & 179 & 717 & M \\
\hline 8 & 10.6 & 175 & 970 & M \\
\hline 9 & 5.7 & 166 & 522 & $\mathrm{~F}$ \\
\hline 10 & 11.6 & 182 & 1063 & M \\
\hline 11 & 7.0 & 171 & 647 & $\mathrm{~F}$ \\
\hline 12 & 8.4 & 173 & 773 & $\mathrm{~F}$ \\
\hline 13 & 5.4 & 161 & 495 & $\mathrm{~F}$ \\
\hline 14 & 6.6 & 165 & 609 & $\mathrm{~F}$ \\
\hline 15 & 5.5 & 164 & 509 & $\mathrm{~F}$ \\
\hline 16 & 7.4 & 168 & 683 & $\mathrm{~F}$ \\
\hline 17 & 16.2 & 182 & 1489 & $\mathrm{~F}$ \\
\hline 18 & 12.1 & 190 & 1112 & M \\
\hline$a n=$ & jiation & $173 \pm 9$ & $767 \pm 262$ & - \\
\hline
\end{tabular}
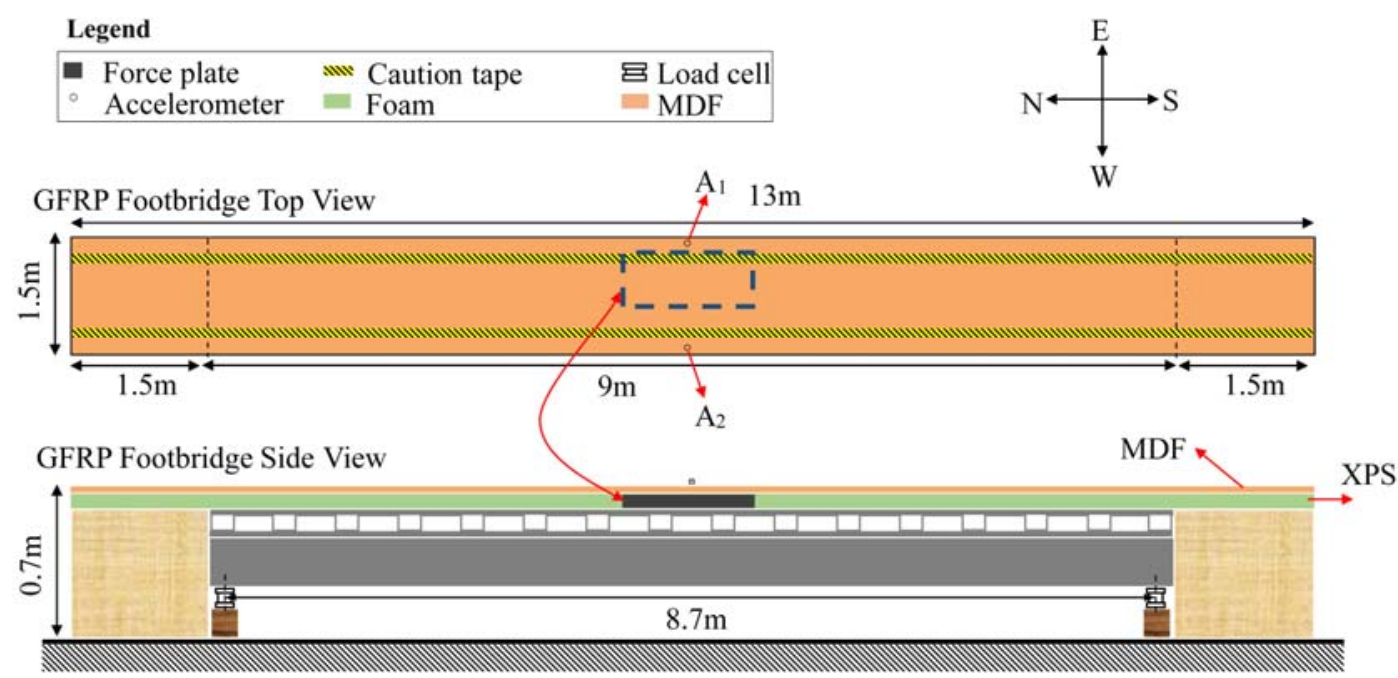

Figure 3. Experiment setup for the footbridge walk ( $A_{1}$ and $A_{2}$ are accelerometers). 
This paper has been published under the following reference: Ahmadi, E., Caprani, C., Zivanovic, S. and Heidarpour, A. Assessment of Human-Structure Interaction on a Lively Lightweight GFRP Footbridge. Engineering Structures. Vol. 199. Nov 2019. DOI: https://doi.org/10.1016/i.engstruct.2019.109687

A sophisticated data collection setup illustrated in Figure 4 was used for simultaneous recording of the GRFs on the bridge surface and the corresponding footbridge vibration. The data from four load cells was recorded by a 4-channel DT9838 module. The data from two accelerometers and force plate were collected by a 16-channel DT9857E module. The QuickDAQ and Teskcan data-logger unit were used to set the acquisition parameters. Each signal was recorded for 20 seconds with sampling frequency of $500 \mathrm{~Hz}$. The 20 -second interval was long enough to capture both the traversing the bridge and some subsequent free vibration decay. The DAQs were synchronised using bespoke wireless triggers to ensure simultaneous recording of all signals.

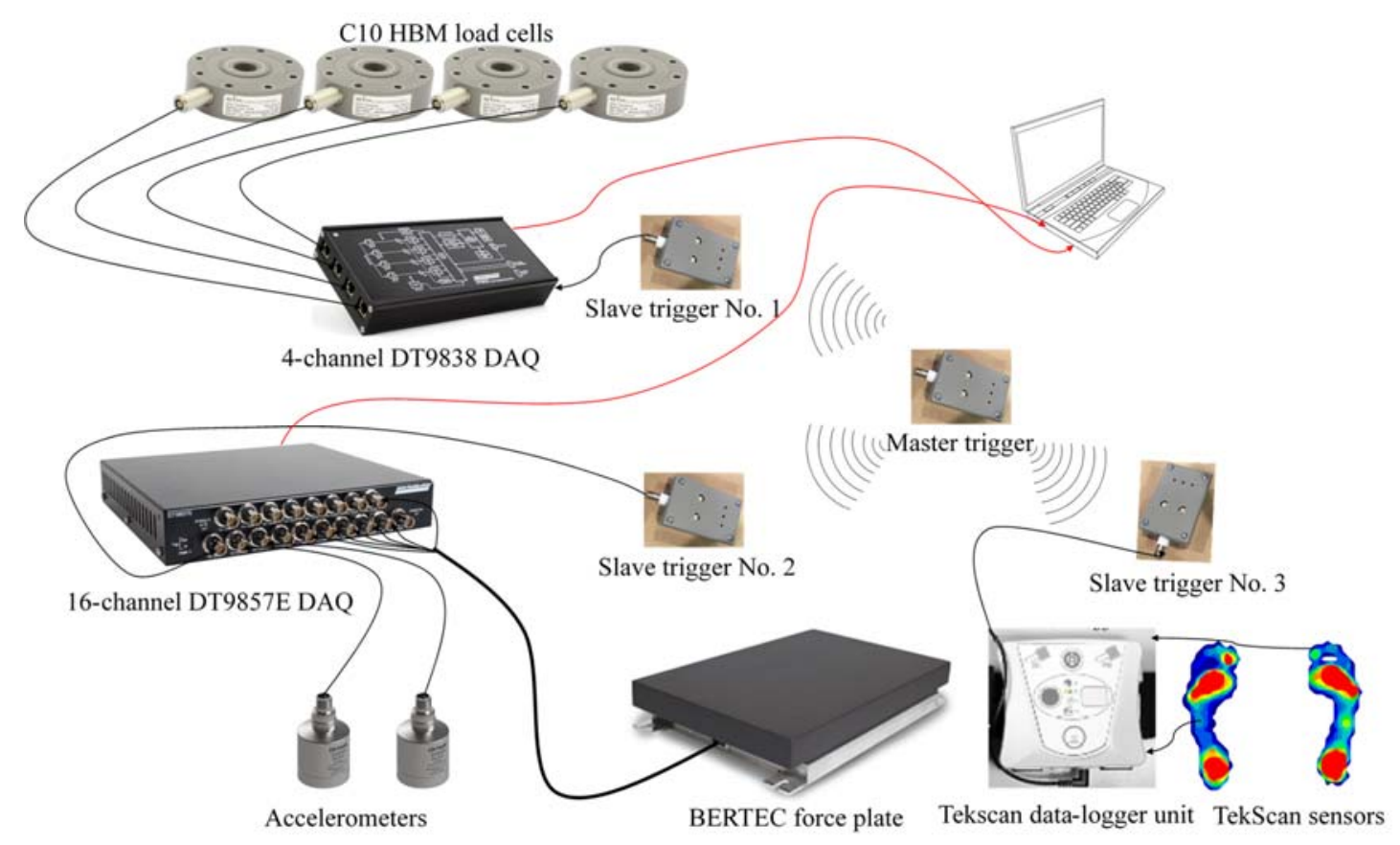

Figure 4. Data collection setup for the bridge walk.

\section{Quantification and Minimisation of Errors}

\subsection{Experimental Setup}

To assess the accuracy of the walking trial results, it is important to understand the influences of potential measurement and calculation errors (see Figure 1). Consequently, the footbridge numerical model error, $\varepsilon N M$, and the accuracy of the walking force measurements, $\varepsilon G$, are 
This paper has been published under the following reference: Ahmadi, E., Caprani, C., Zivanovic, S. and Heidarpour, A. Assessment of Human-Structure Interaction on a Lively Lightweight GFRP Footbridge. Engineering Structures. Vol. 199. Nov 2019. DOI:

https://doi.org/10.1016/i.engstruct.2019.109687

quantified. The precisions of load cells and force plate were also examined by conducting a

shaker test. Further, the Tekscan system error was examined, quantified, and minimized using the force plate results from the main walking experiments.

Figure 5 shows the experimental setup used to determine the footbridge numerical model error and the force measurement errors of the load cells and force plate. The GFRP footbridge was excited by an APS 113 ELECTRO series electrodynamic shaker placed in the middle of the footbridge using an amplitude-constant sinewave of frequency ranging from 5.0-5.7 Hz with increment of $0.1 \mathrm{~Hz}$. An accelerometer was attached to the shaker armature, $a_{s h}$, the reading of which is multiplied by the armature mass $(12.3 \mathrm{~kg})$ to give the shaker force applied to the footbridge, $G_{s h}$. Low and high-amplitude vibrations were imposed. Ten accelerometers were placed along the footbridge centreline to target the first bending mode. The shaker excitation lasted for 90 seconds to reach a steady-state response and then the footbridge entered free vibration for 30 seconds. Figure 6 shows an example set of readings for an excitation frequency of $5.4 \mathrm{~Hz}$ using high-amplitude vibration where $a_{b}, G_{l c}$, and $G_{f p}$ are footbridge acceleration, load cells force, and force plate reading respectively. The first 10 seconds or so of the excitation shows a transient response leading to a steady-state response.

Only the dominant bending mode is considered (see Figure 7). The properties of this mode are found using the test results, similar to Figure 6 . The free decay vibration at the mid-span (accelerometers 5 and 6 in Figure 7) were used to determine the damping and frequency of the bridge-shaker system, $\xi_{b s}$ and $f_{b s}$ by fitting an exponential decay curve (Figures $8 \mathrm{a}$ and $8 \mathrm{~b}$ ). Both the damping and frequency of the system can be seen to reduce with increasing vibration amplitude. Compared to the empty bridge, the presence of the shaker (mass of $51 \mathrm{~kg}$ ) reduces the system's first natural frequency (to $5.6 \mathrm{~Hz}$ ) and increases its damping ratio (to around $0.6 \%$ ). Clearly, the shaker's spring-mounted armature acts as a damper on the system. 
This paper has been published under the following reference: Ahmadi, E., Caprani, C., Zivanovic, S. and Heidarpour, A. Assessment of Human-Structure Interaction on a Lively Lightweight GFRP Footbridge. Engineering Structures. Vol. 199. Nov 2019. DOI:

https://doi.org/10.1016/i.engstruct.2019.109687

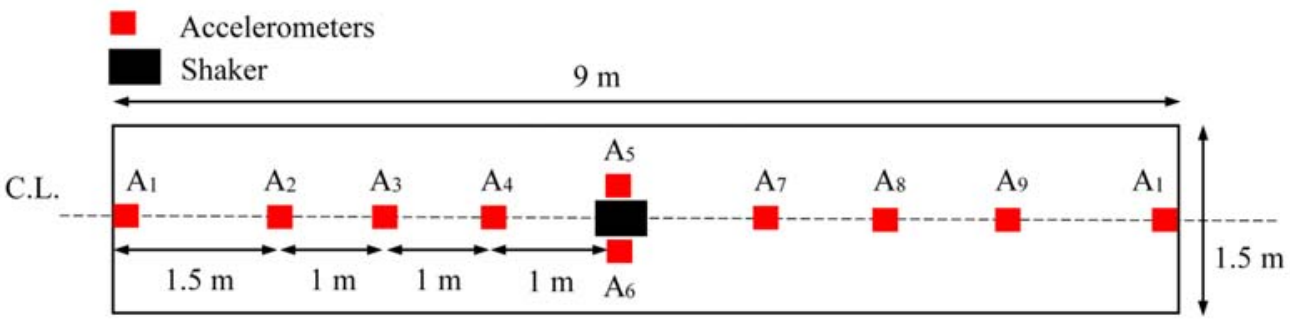

Figure 5. Accelerometers and shaker arrangement.
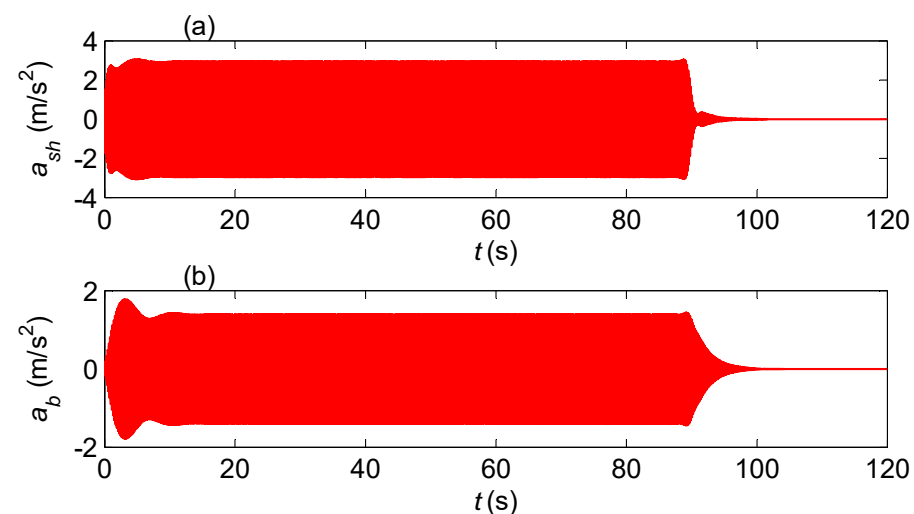

(c)
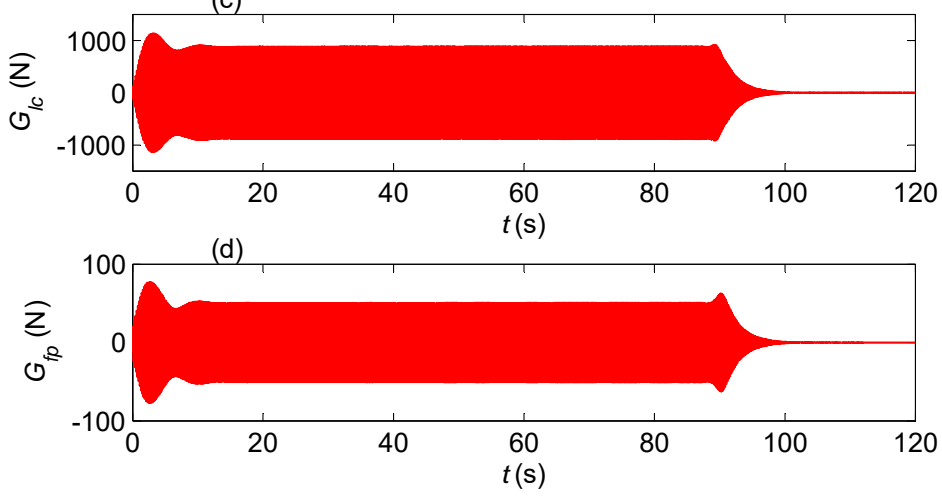

Figure 6. Time history of (a) shaker acceleration; (b) accelerometer no. 5; (c) load cells, and; (d) force plate for excitation frequency of $5.4 \mathrm{~Hz}$ (when the armature mass stops moving it causes an impulse load visible in the force time histories).

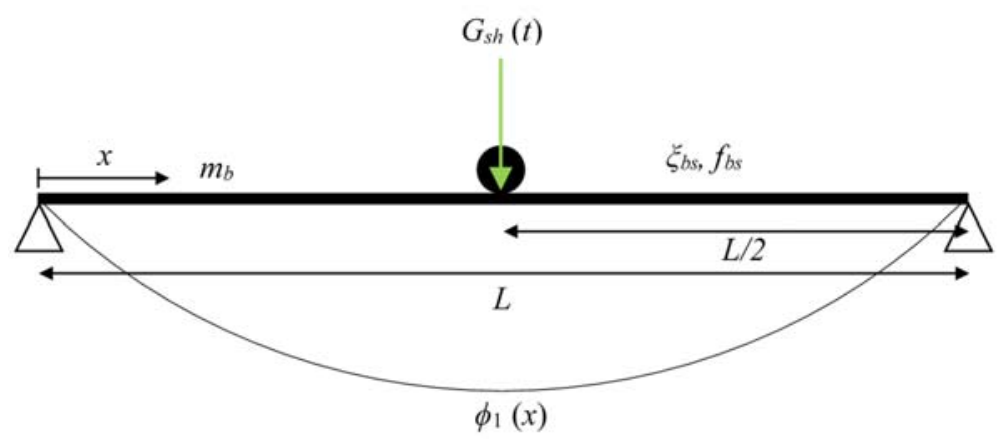

Figure 7. Numerical model and mass distribution of the bridge-shaker system. 
This paper has been published under the following reference: Ahmadi, E., Caprani, C., Zivanovic, S. and Heidarpour, A. Assessment of Human-Structure Interaction on a Lively Lightweight GFRP Footbridge. Engineering Structures. Vol. 199. Nov 2019. DOI:

https://doi.org/10.1016/i.engstruct.2019.109687

To determine the mode shape, the acceleration time histories were transformed to frequency domain using Fast Fourier Transform (FFT), and the imaginary part of the FFTs at the vibration frequency (around $5.3 \mathrm{~Hz}$ ) were used. The mode shape of the footbridge is plotted in Figure 8c, as estimated separately from the free decay vibration response and the steady-state response of the footbridge-shaker system. Due to its support arrangement, the mode shape is very close to that for simply-supported beams,

$$
\phi_{1}(x)=\sin \left(\frac{\pi x}{L}\right)
$$

as can be observed in Figure 8c. Figure 8 also shows that the shaker mass does not appreciably affect the mode shape. The modal mass of the footbridge-shaker system is calculated as $526 \mathrm{~kg}$, treating the shaker as a lumped mass on the middle of the footbridge (Figure 7).
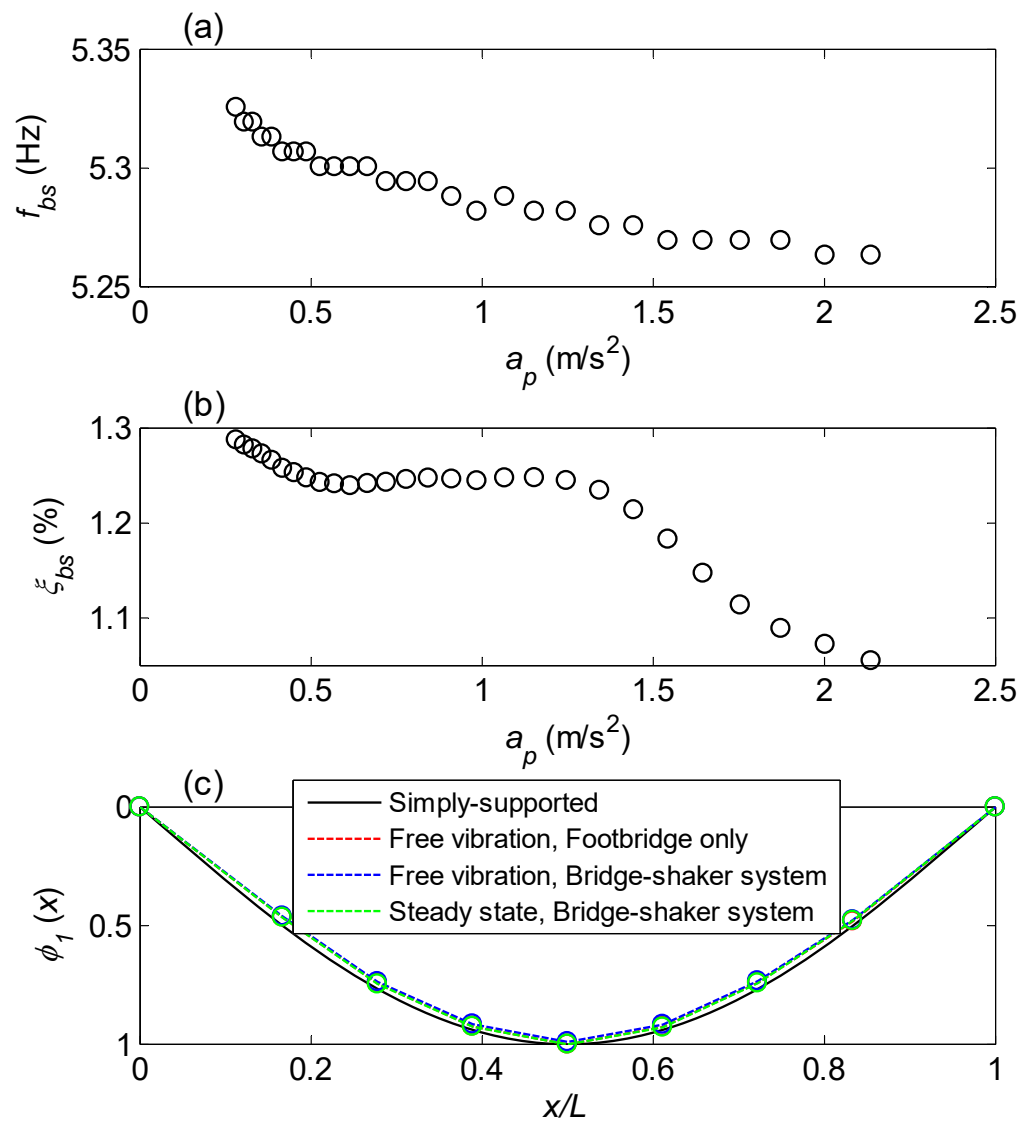

Figure 8. Bridge-shaker system: (a) frequency, (b) damping, and (c) mode shape. 


\subsection{Numerical model of the bridge}

Using the standard modal space approach (e.g. Chopra [38] or Humar [39]), the equation of motion for the bridge-shaker system subjected to the dynamic shaker force, $G_{s h}(t)$, at the midspan (see Figure 7) is given by:

$$
\ddot{q}_{1}+2 \xi_{b s} \omega_{b s} \dot{q}_{1}+\omega_{b s}^{2} q_{1}=\frac{1}{M_{b s}} \phi_{1}\left(\frac{L}{2}\right) G_{s h}(t)
$$

where $\xi_{b s}, \omega_{b s}$, and $M_{b s}$ are the bridge-shaker system's modal damping, frequency, and mass respectively. For a harmonic force of frequency, $\omega$, and amplitude, $G_{s h 0}$, $\left(G_{s h}(t)=G_{s h 0} \sin (\omega t)\right)$, the steady-state response closed form solution of equation (3) is (e.g.

Den Hartog [40]:

$$
a_{b s}^{e}=\frac{G_{s h 0} \beta^{2}}{M_{b s} \sqrt{\left(1-\beta^{2}\right)^{2}+\left(2 \xi_{b s} \beta\right)^{2}}}
$$

where $\beta$ is the excitation-to-system frequency ratio, $\omega \omega_{b s}$, and $a_{b s}^{e}$ is the estimated vibration response of the bridge-shaker system.

The measured steady-state responses, $a_{b s}^{m}$, and those estimated from equation (4), $a_{b s}^{e}$, are shown against the frequency ratio in Figure 9a. The numerical model based on the modal properties obtained above are found to estimate the measured steady-state response with reasonable precision. The relative error between estimated and measured steady-state responses is:

$$
\varepsilon_{N M}=100 \frac{a_{b s}^{e}-a_{b s}^{m}}{a_{b s}^{m}}
$$

and they are seen to fall within the range of $\pm 10 \%$ for a range of excitation frequencies around resonance (Figure 9b), regardless of the vibration amplitude. 
(a)

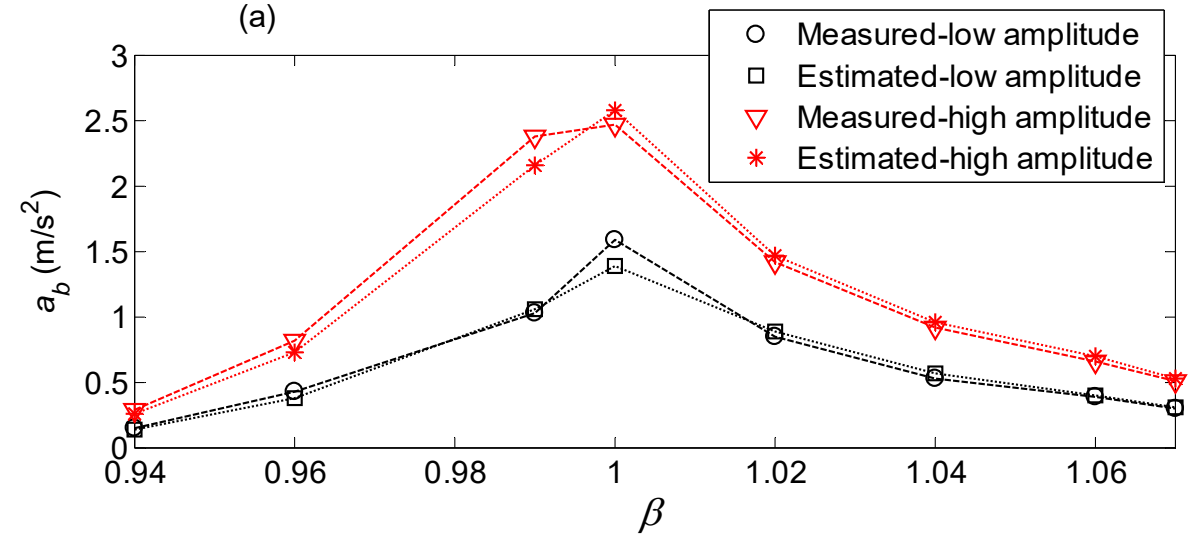

(b)

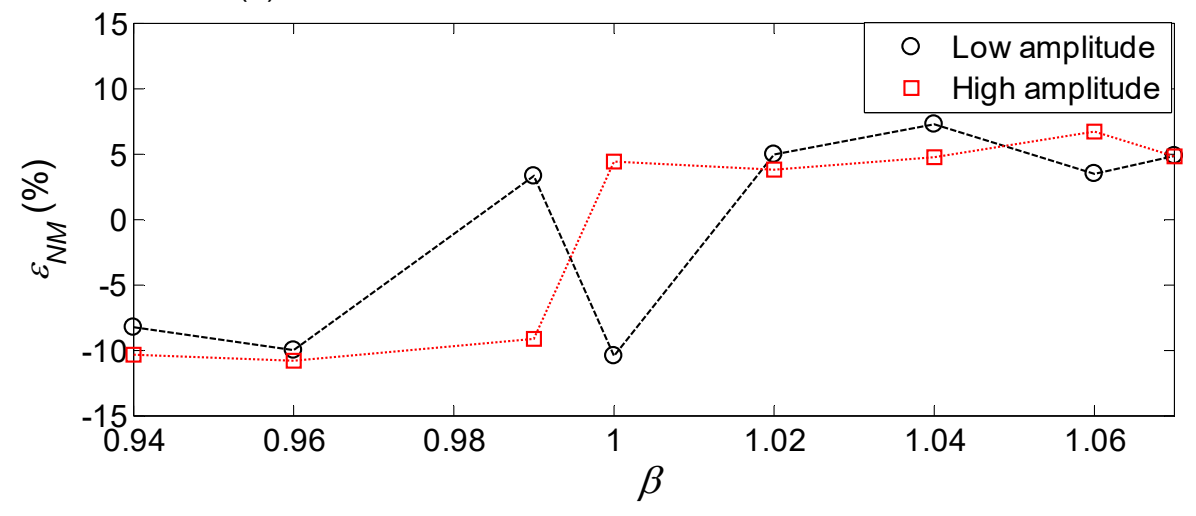

Figure 9. (a) Measured and estimated steady-state response, (b) relative error between measured and estimated steady-state responses for both low- and high-amplitude vibrations.

\subsection{Accuracy of force plate and load cells}

To estimate the accuracy of the load cells and force plate, the shaker's applied force is taken as the reference. For the load cells, Glc (Figure 6c), the total force comprises the applied shaker force, $G_{s h}$, and the bridge-shaker system inertial force, $G_{I}$. Similarly, for the force plate, it is mounted on the vibrating surface of the footbridge which influences the reading. Ahmadi et al. [22] described how the relevant effective masses are calculated, and the inertial forces caused by the footbridge vibration removed from the load cells and force plate readings.

Figure 10a compares the load cells force and force plate reading with the shaker's applied force for a few vibration cycles and an excitation frequency of $5.4 \mathrm{~Hz}$. As seen, the frequency of both force plate and load cells signal are very similar to the shaker's force, and there is a very slight shift in the time domain between the force plate or load cells reading and the shaker's force (- 
This paper has been published under the following reference: Ahmadi, E., Caprani, C., Zivanovic, S. and Heidarpour, A. Assessment of Human-Structure Interaction on a Lively Lightweight GFRP Footbridge. Engineering Structures. Vol. 199. Nov 2019. DOI:

https://doi.org/10.1016/i.engstruct.2019.109687

0.01 and 0.01 second shift for the force plate and load cells forces), presumably due to different time constant for different sensors in the accelerometer on the shaker, force plate, and load cells. Figure 10a also shows the high accuracy of both the load cells and the force plate in the force amplitude measurement. The relative errors between the steady-state amplitude of these devices and the shaker are calculated as:

$$
\varepsilon_{G}=100 \frac{G_{d}-G_{s h}}{G_{s h}}
$$

in which $G_{d}$ is either the amplitude of the force plate reading or the load cells force, and the shaker's force amplitude is taken as the reference. Figure $10 \mathrm{~b}$ shows the amplitude relative error results for both the load cells and the force plate using equation (6). The errors fall within the range $\pm 3 \%$ for both the load cells and the force plate for a range of excitation frequencies around resonance (see Figure 1, part (c)).

(a)

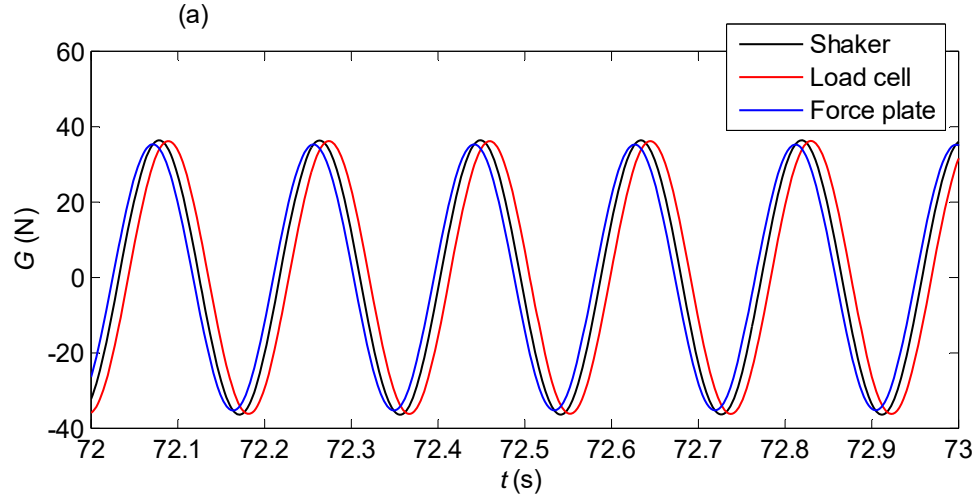

(b)

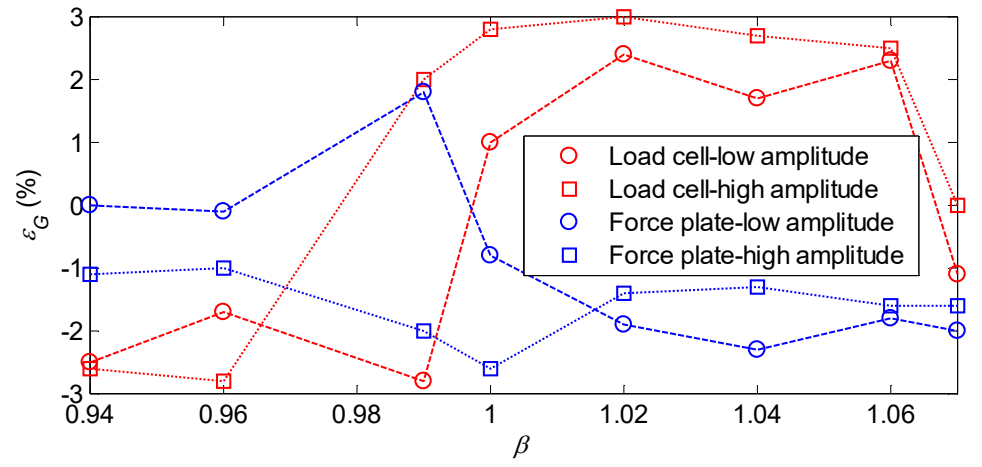

Figure 10. (a) Comparison of shaker force with the load cells force and the force plate reading for a few vibration cycles, (b) relative errors of load cells and force plate force amplitude. 
This paper has been published under the following reference: Ahmadi, E., Caprani, C., Zivanovic, S. and Heidarpour, A. Assessment of Human-Structure Interaction on a Lively Lightweight GFRP Footbridge. Engineering Structures. Vol. 199. Nov 2019. DOI: https://doi.org/10.1016/i.engstruct.2019.109687

\subsection{Tekscan F-scan accuracy}

As noted earlier, to measure GRFs on both rigid and bridge surfaces (Figure 1, parts (b) and (c)), Tekscan F-scan in-shoe pressure sensors ([37], [41]) were used (Figure 11). The sensors consist of many capacitors arranged in rows and columns, termed 'sensels'. The raw sensor outputs are converted to pressure readings using calibration. Five methods of sensor calibration are possible, but the "walk calibration" was found to give higher accuracy [24], and so was performed every 5 trials for each test subject. The plantar pressure readings from the sensors are integrated to produce an estimate of the vertical component of the GRF for each foot individually.

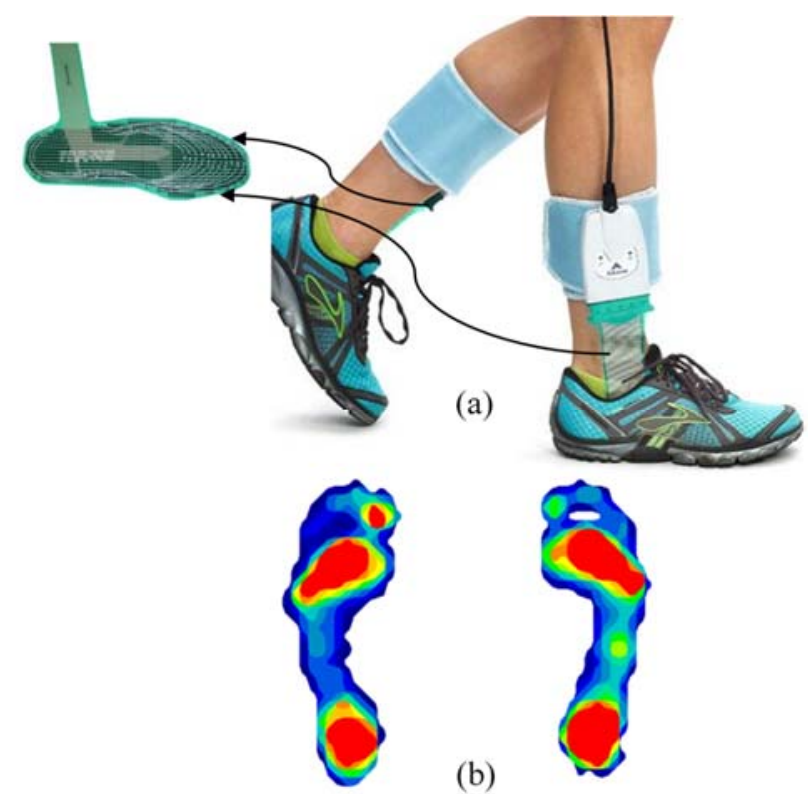

Figure 11. Tekscan F-scan in-shoe sensors: (a) instrument, (b) example output pressure distribution ([35].

To estimate error in the Tekscan readings, the force plate readings of single footsteps are used as the reference. A numerical procedure was used to identify complete footsteps on the force plate [22]. The sample rate is the same for both the force plate and Tekscan and so time is indicated by the index, $i$. Index $j$ is used to denote a specific trial of which there are $N \leq 15$ trials with complete footsteps on the force plate for each test subject and pacing frequency. The Tekscan measurement relative error for trial $j$ at time $i$ is: 


$$
\varepsilon_{i j}^{t s}=\frac{G_{i j}^{t s}-G_{i j}^{f p}}{G_{i j}^{f p}}
$$

and the mean relative error at time $i$ is:

$$
\bar{\varepsilon}_{i}^{t s}=\frac{1}{N} \sum_{j=1}^{N} \varepsilon_{i j}^{t s}
$$

The mean relative error is used as the Tekscan error, $\varepsilon_{G}$. Figure 12 shows the recorded force time histories and relative error between force plate and Tekscan for each step as well as the mean relative error for test subject no 2 at the resonance. The figure illustrates that the dispersion is quite low (low standard deviation), particularly for the region of most interest (middle part of each footstep, i.e. when the readings are non-negligible). Analysis of Tekscan errors for all test subjects and pacing frequencies showed that Tekscan error changes between different test subjects and pacing frequencies. Therefore, a mean relative error was determined for each set of trials.

In the numerical model that follows, it is necessary to model the true walking forces based on the Tekscan measurements. The following procedure is used to reconstruct a footstep GRF from a Tekscan GRF, allowing for the measurement error:

1. Select an individual footstep from the Tekscan signal for the trial.

2. Use the mean relative error to generate a representative footstep (which will be similar to that measured by the force plate):

$$
G_{i}^{f p}=G_{i}^{t s}\left(1+\bar{\varepsilon}_{i}^{t s}\right)
$$

3. Repeat steps 1 and 2 for all footsteps of Tekscan GRF for each feet.

4. Add the generated footsteps to create a full-trial walking force-time history. 
(a)

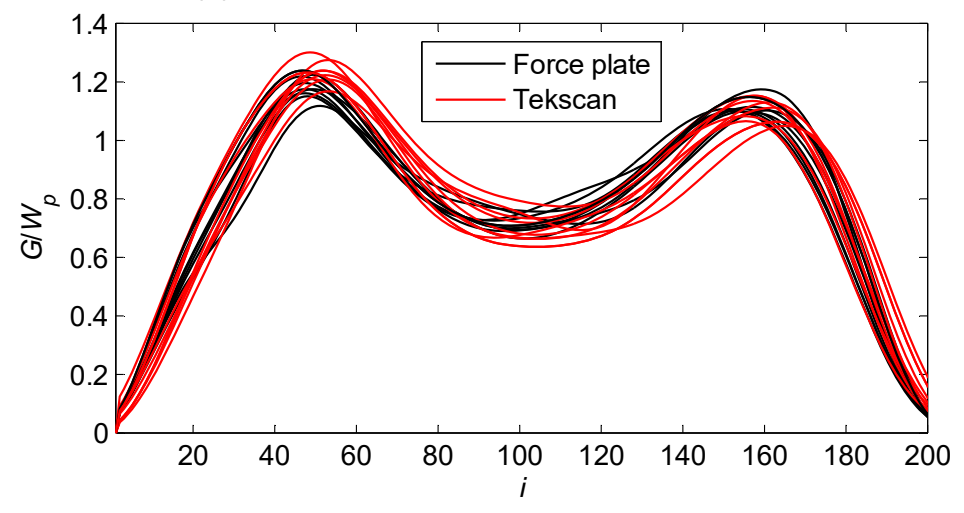

(b)

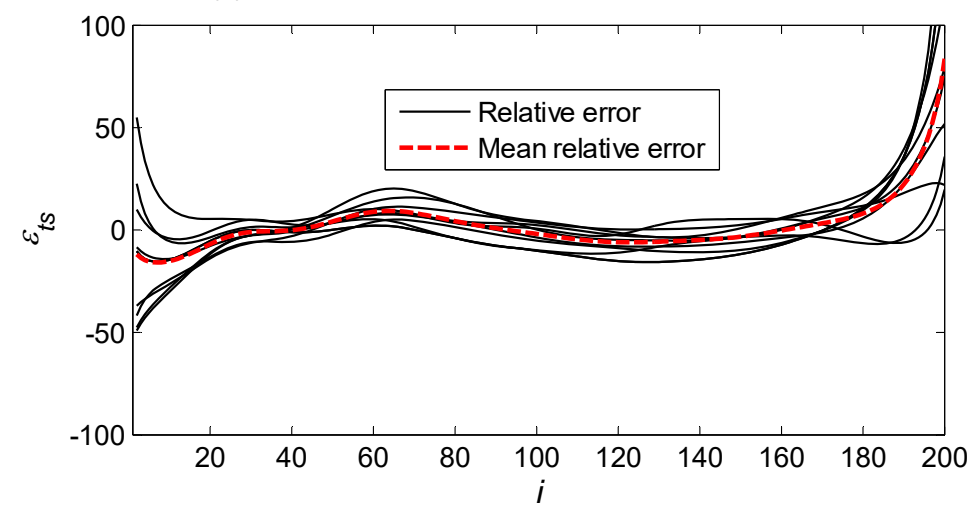

Figure 12. (a) Force plate and Tekscan readings, (b) relative errors for test subject no. 2 at resonance.

\section{Experiments with People Walking}

\subsection{Measured vibration response}

Figure 13a shows the auto-spectral density (ASD) of the accelerometer signals (see $\mathrm{A}_{1}$ and $\mathrm{A}_{2}$ in Figure 3) for test subject no. 2 and trial no. 9 at the resonance (this test subject and trial are used as an example throughout the paper). The ASD has high amplitude at the first bending mode at $5.6 \mathrm{~Hz}$ and it is much lower at other frequencies, i.e most of the footbridge vibration energy is distributed in the range 5-6 Hz. The mean of the two acceleration signals is taken as the footbridge vibration response at mid-span (Figure 13b). To focus solely on the first bending mode, the footbridge vibration responses are filtered using a zero-phase 4th order band-pass Butterworth filter with range 5-6 Hz (Figure 13b). This filter has a fast roll-off and is thus appropriate for narrow frequency ranges. The response envelope exhibits a double hump shape 
This paper has been published under the following reference: Ahmadi, E., Caprani, C., Zivanovic, S. and Heidarpour, A. Assessment of Human-Structure Interaction on a Lively Lightweight GFRP Footbridge. Engineering Structures. Vol. 199. Nov 2019. DOI:

https://doi.org/10.1016/i.engstruct.2019.109687

which may arise from a beat phenomenon caused by pacing frequency being close to the footbridge frequency [42]. This phenomenon is more noticeable in low-damping systems [43] such as the Monash footbridge.

(a)

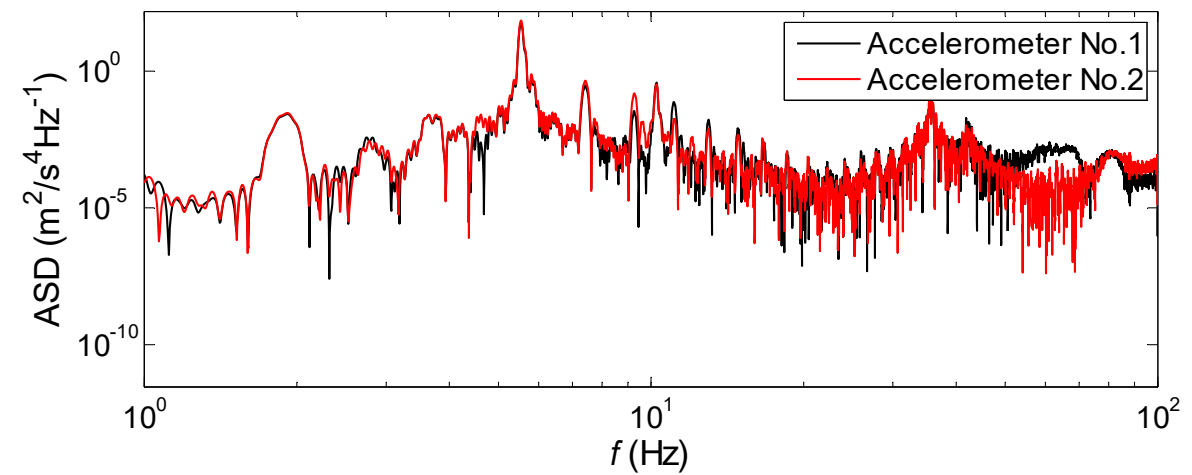

(b)

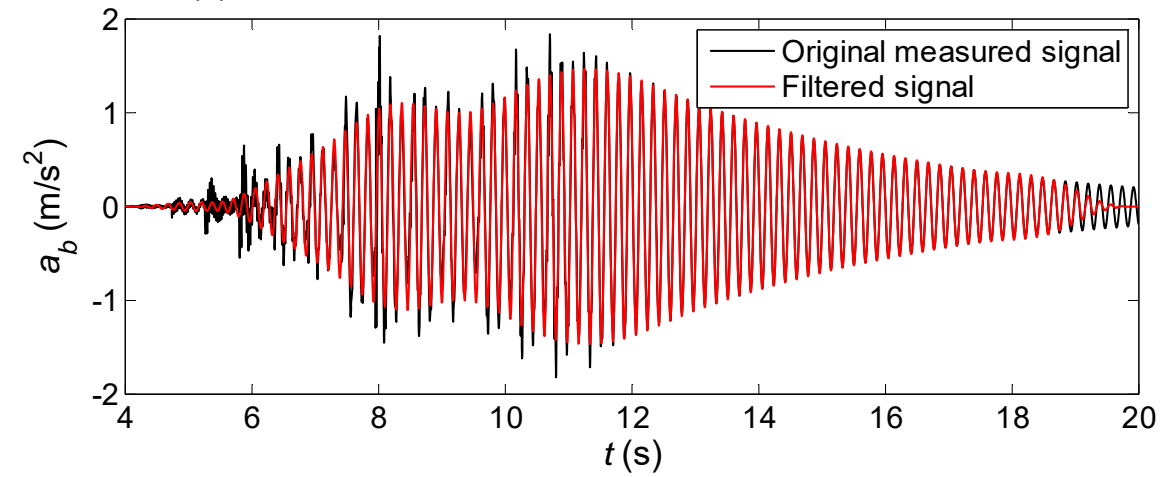

Figure 13. (a) Auto spectral density (ASD) of the original signal, (b) footbridge mid-span acceleration response for the exemplary test subject (the tapering at the end of the filtered signal is an artefact of the filter).

\subsection{Modal parameters}

The damping and frequency of the footbridge (that includes the installed force plate) were determined from the free decay vibration part of the acceleration signal for each trial. Both are found for a moving window of five peaks. An exponential decay curve was fitted (using leastsquares) for the damping. Figure 14 shows the results for the exemplary test subject. For this trial, the damping does not change significantly with amplitude, while the frequency slightly decreases with increasing vibration amplitude. 
(a)

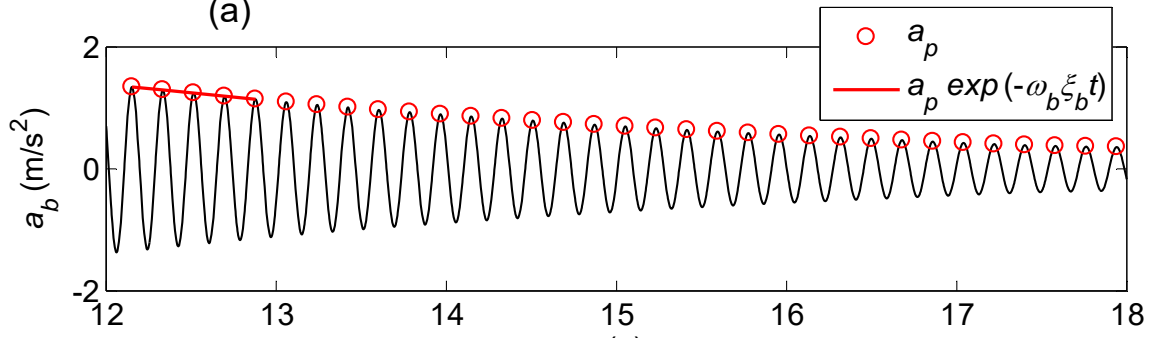

(b)

$t(\mathrm{~s})$

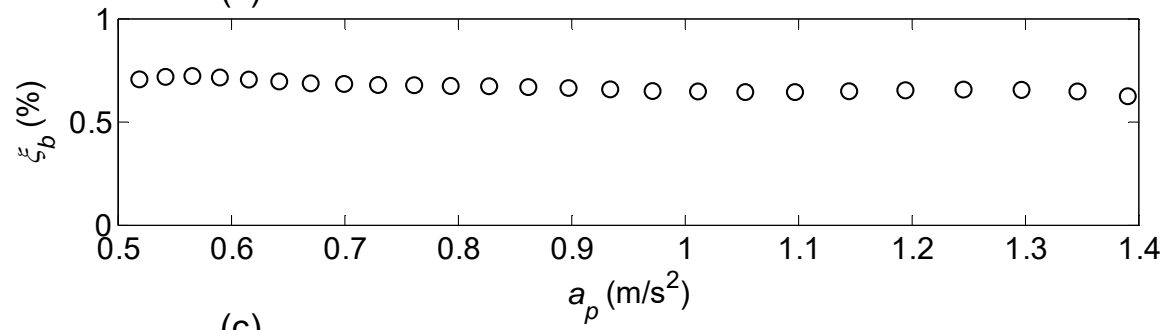

(c)

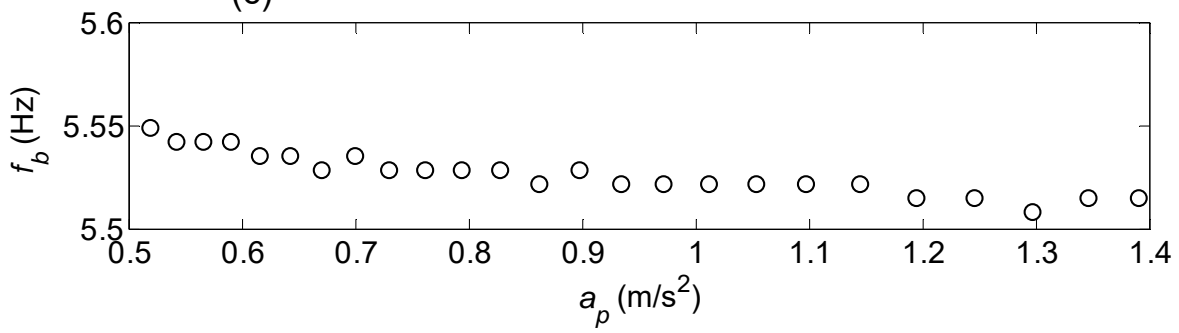

Figure 14. (a) Free vibration part of the mid-span acceleration (b) amplitude-dependent damping (c) amplitude-dependent frequency for the exemplary test subject.

The frequency and damping determined for all trials are shown against vibration amplitude in Figure 15. The data were collected over six months from October 2016 to March 2017 with average temperature variation range $13-23{ }^{\circ} \mathrm{C}$. The wide dispersion of the results between trials could indicate the significance of environmental effects, such as temperature changes. It has been shown that temperature increase can highly reduce bridge frequency and increase its damping [44]. Further study is underway to quantify these effects, but to include these effects here, the free decay vibration frequency and damping results for each trial are used in further analysis. 
(a)

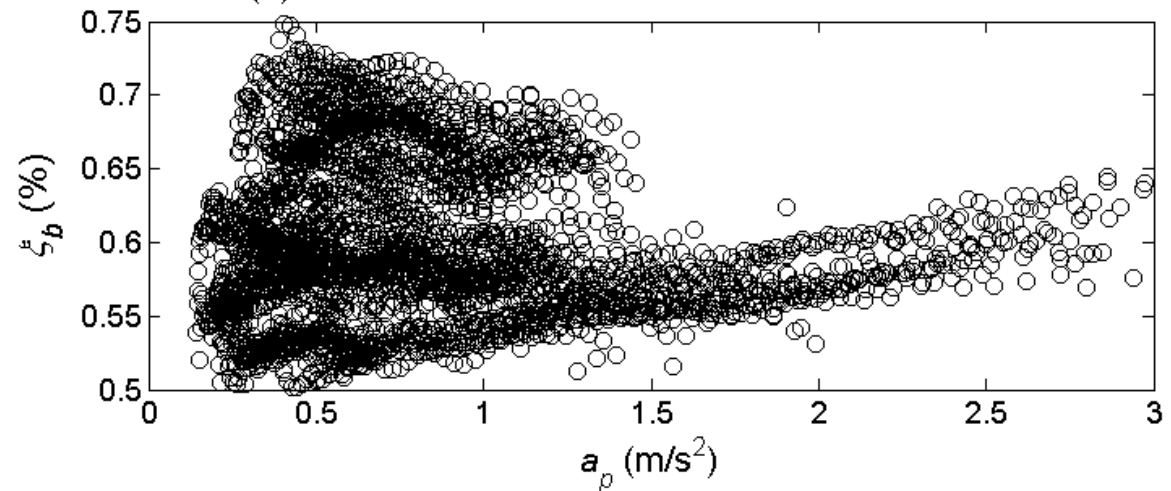

(b)

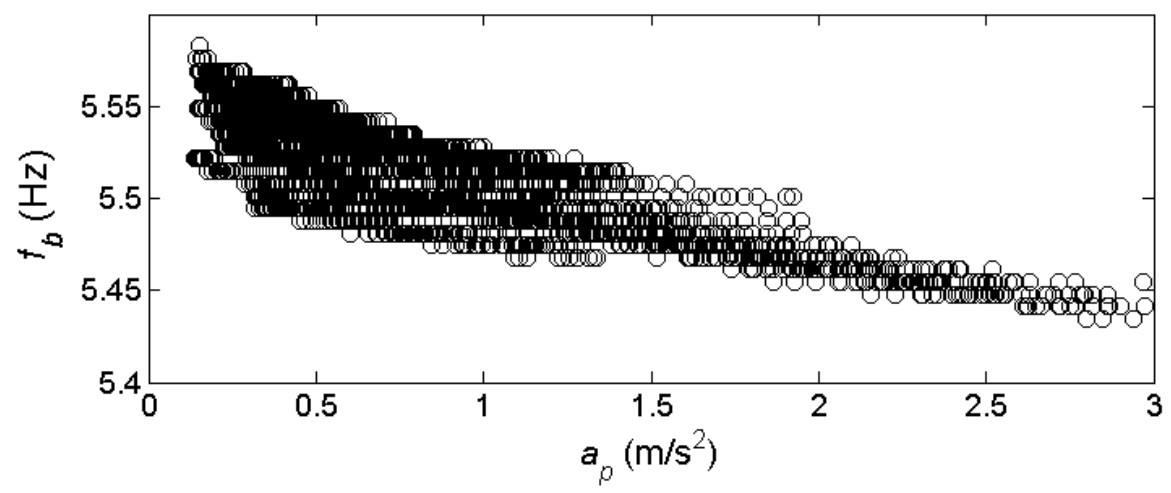

Figure 15. (a) Bridge damping, (b) bridge frequencies from free decay response for all trials.

The inertial mass of the footbridge alone is required to remove the effects of vibration on the load cells' readings. Without the shaker (which was described earlier), the inertial mass of the footbridge only, $M_{I}$, was found to be $610 \mathrm{~kg}$ using the free vibration part of the acceleration and load cells force signals [22].

The modal mass of the footbridge, $M_{b}$, was determined using three mutually-confirming approaches. First, treating the force plate as a lumped mass at mid-span and using the simplysupported mode shape as discussed earlier gives:

$$
\begin{aligned}
M_{b} & =\left[\int_{0}^{L} m(x) \phi_{1}(x)^{2} d x\right] \\
& =\frac{m_{b} L}{2}+M_{f p}
\end{aligned}
$$


This paper has been published under the following reference: Ahmadi, E., Caprani, C., Zivanovic, S. and Heidarpour, A. Assessment of Human-Structure Interaction on a Lively Lightweight GFRP Footbridge. Engineering Structures. Vol. 199. Nov 2019. DOI:

https://doi.org/10.1016/i.engstruct.2019.109687

where $m_{b}$ is mass per unit length of the covered footbridge excluding the force plate. The mass

per unit length of the covered bridge without the force plate is $100.1 \mathrm{~kg} / \mathrm{m}$, see Figure 7 . The force plate weights $38 \mathrm{~kg}$, and so the modal mass is finally calculated as $489 \mathrm{~kg}$. The second method uses the inertial mass and again treats the force plate as a lumped mass at the mid-span and the footbridge as a uniformly distributed mass:

$$
\begin{aligned}
M_{I} & =\left[\int_{0}^{L} m(x) \phi_{1}(x) d x\right] \\
& =\frac{2 L}{\pi} m_{b}+M_{f p}
\end{aligned}
$$

Substituting the force plate mass and the footbridge inertial mass in equation (11) gives $m_{b}=99.8 \mathrm{~kg} / \mathrm{m}$, giving a modal mass of $487 \mathrm{~kg}$ using equation (10). For the third approach, it is considered that the additional covering does not add extra stiffness to the footbridge and it only changes the footbridge mass. Therefore:

$$
M_{u b} f_{u b}^{2}=M_{b} f_{b}^{2}
$$

where subscript $u b$ stands for uncovered footbridge. An experimental modal analysis of the uncovered bridge resulted in $M_{u b}=417 \mathrm{~kg}$ and $f_{u b}=6.0 \mathrm{~Hz}$, whilst the free vibration of the covered bridge on the same day at high-amplitude vibrations results in $f_{b}=5.55 \mathrm{~Hz}$. It then follows that $M_{b}=487 \mathrm{~kg}$. The three methods led to almost the same modal mass estimates at $487 \mathrm{~kg}$, providing confidence in accuracy of the estimate. This is important since the modal mass parameter is most difficult of all to determine accurately [45]. Further, the consistency of the estimate indicates that the simply-supported mode shape and uniformly distributed mass are valid assumptions for the footbridge numerical model. Furthermore, the inertial mass of the footbridge is also seen to be consistent.

\subsection{Location of test subject's resultant force}

For vibration response simulations using a discrete footfall moving force model, it is necessary to know the precise location of test subjects' force resultant throughout the trial [46], [47]. This is approximately the same as the feet location assuming that the walking force acts at a point 
This paper has been published under the following reference: Ahmadi, E., Caprani, C., Zivanovic, S. and Heidarpour, A. Assessment of Human-Structure Interaction on a Lively Lightweight GFRP Footbridge. Engineering Structures. Vol. 199. Nov 2019. DOI:

https://doi.org/10.1016/i.engstruct.2019.109687

not an area, tough may vary during toe-off or heel-strike somewhat. In addition, the test subject

velocity is determined from their longitudinal trajectory and used in the moving force models [17], [26].

The trajectory of the walking force on the footbridge surface is found from the load cell readings at each time instant using equilibrium (see Figure 16):

$$
\begin{gathered}
x_{p}(t)=\frac{G_{l c 1}(t)+G_{l c 2}(t)}{G_{l c}(t)} L \\
y_{p}(t)=\frac{G_{l c 2}(t)+G_{l c 4}(t)-G_{l c 1}(t)-G_{l c 3}(t)}{2 G_{l c}(t)} W
\end{gathered}
$$

where $x_{p}$ and $y_{p}$ are the longitudinal and transverse locations of the walking force; $G_{l c i}(t)$, is the force at load cell $i ; G_{l c}(t)$ is the total force $\sum_{i} G_{l c i}(t)$, and; $L$ and $W$ are the longitudinal and transverse distances between centres of the load cells.

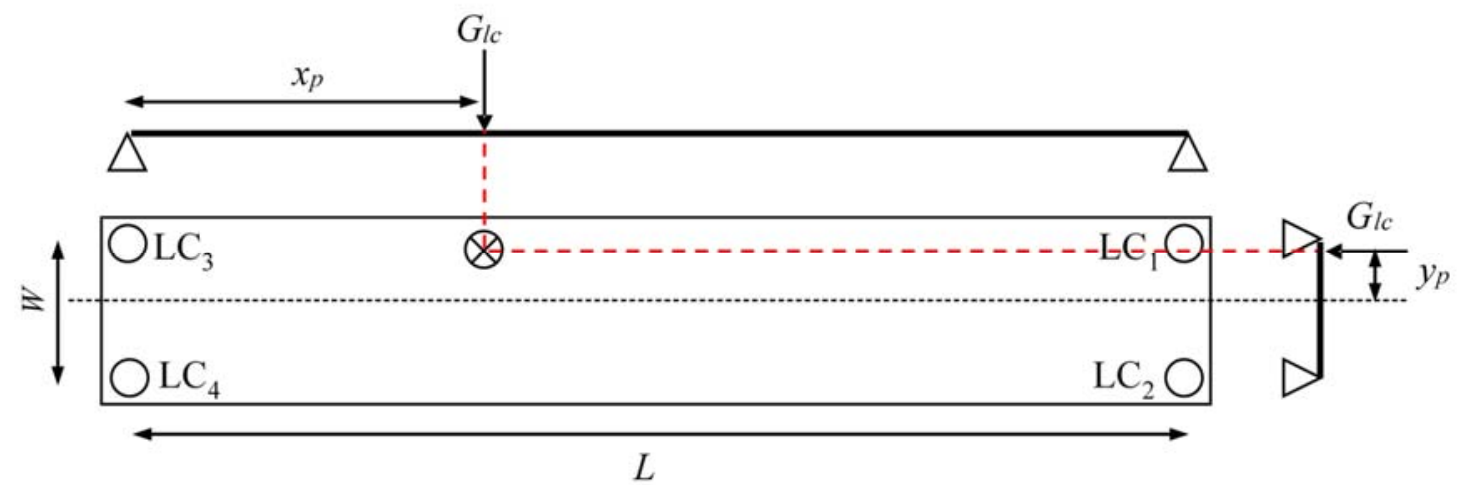

Figure 16. Load cells location and test subjects' force location (red dashed lines show the vertical and horizontal locations of a general test subject at a specific time instant).

Figures $17 \mathrm{a}$ and $17 \mathrm{~b}$ show the walking force evolution for the exemplary test subject and trial. The corresponding Tekscan results are illustrated in Figure 17c. The calculated extrema of the transverse force trajectory (Figure 17a) correspond to the mid-stance phase of the gait for the foot in contact with the ground (see the force form the Tekscan measurements in Figure 17c). Therefore, the calculated values signify a discrete, i.e. single contact point, representation of 
This paper has been published under the following reference: Ahmadi, E., Caprani, C., Zivanovic, S. and Heidarpour, A. Assessment of Human-Structure Interaction on a Lively Lightweight GFRP Footbridge. Engineering Structures. Vol. 199. Nov 2019. DOI:

https://doi.org/10.1016/i.engstruct.2019.109687

human foot's location. In this running example, the test subject's right foot first touches the

footbridge. The longitudinal trajectory of the test subject (see Figure 17b) is very close to a straight line, indicating that the test subject maintained a constant velocity during the traverse $(1.17 \mathrm{~m} / \mathrm{s}$ in this example).

(a)

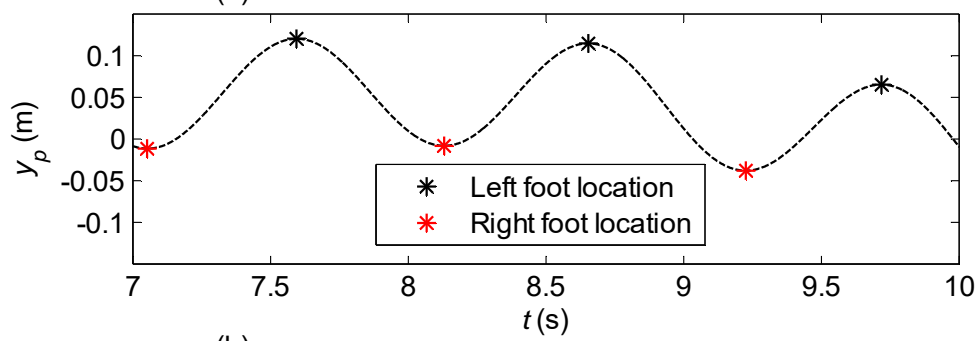

(b)

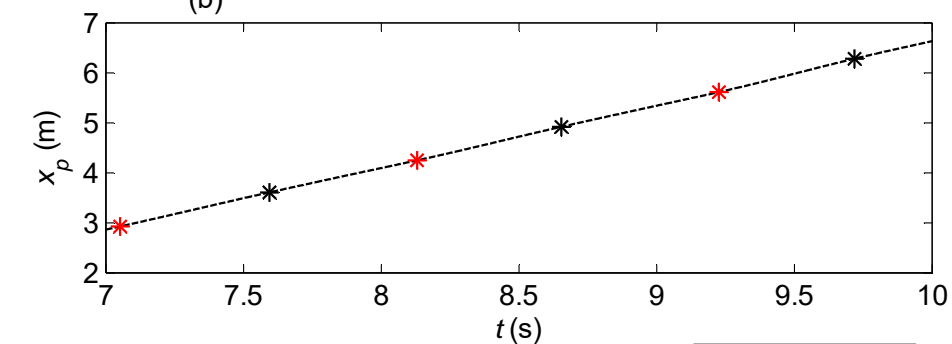

(c)

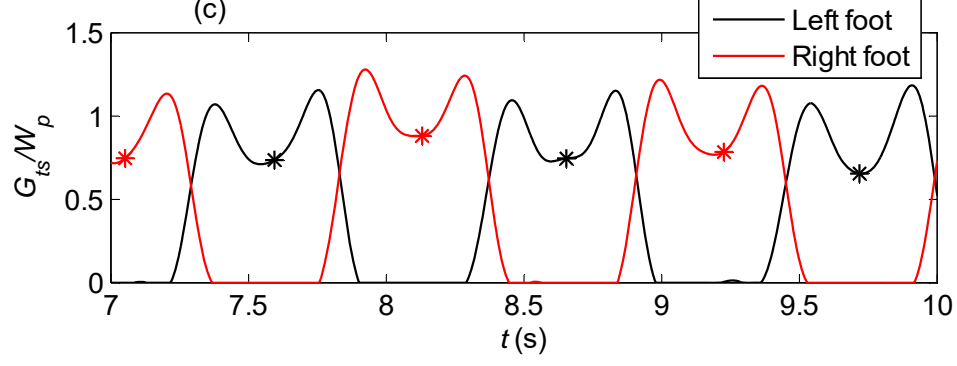

Figure 17. Approximate feet and force resultant trajectories: (a) Transverse, (b) longitudinal walking force trajectories, and (c) Tekscan force results for the exemplary test subject and trial at resonance.

\section{Vibration Response Simulation}

Following the experimental-numerical programme (Figure 1), the vibration responses of the footbridge due to the walking forces measured on both the bridge and rigid surfaces as well as current force models are simulated to assess accuracy of current force models (Aim 1) and quantify the different postulated forms of HSI (Aim 2). 
This paper has been published under the following reference: Ahmadi, E., Caprani, C., Zivanovic, S. and Heidarpour, A. Assessment of Human-Structure Interaction on a Lively Lightweight GFRP Footbridge. Engineering Structures. Vol. 199. Nov 2019. DOI:

\section{https://doi.org/10.1016/i.engstruct.2019.109687}

\subsection{Cycle-by-cycle analysis}

As the footbridge damping and frequency are amplitude-dependent (see Figures 14 and 15), these parameters are updated on a cycle-by-cycle basis (see section 4.2). Vibration cycle $n$ is defined as the vibration response between two consecutive vibration peaks, $a_{p, n-1}$ and $a_{p, n}$ The equation of motion for the $n$th vibration cycle is then given by the modal equation:

$$
\ddot{q}_{1}(t)+2 \xi_{b, n} \omega_{b, n} \dot{q}_{1}(t)+\omega_{b, n}^{2} q_{1}(t)=G^{m}(t)
$$

where $t_{n-1} \leq t \leq t_{n}$ and $t_{n-1}, t_{n}$ are the start and end time of the cycle $n$, respectively corresponding to $a_{p, n-1}$ and $a_{p, n} ; \omega_{b, n}=2 \pi f_{b, n}$ is the circular frequency for the $n$th cycle; $f_{b, n}$ and $\xi_{b, n}$ are the footbridge frequency and damping for the $n$th cycle. The bridge damping and frequency data are determined using linear interpolation at $a_{p, n-1}$ from the free decay vibration response for the specific trial (see Figures $14 \mathrm{~b}$ and 14c).

\subsection{Bridge and rigid surface simulated vibration responses}

Walking force, $G(t)$, is often modelled as a spatially-continuous constant-velocity moving force [9], [48]. This assumption approximates the true spatially-discrete nature of loading from footsteps. As such, the continuous moving force models are more suitable for longer-span footbridges [49]. The continuous modal force of equation (15) is then given by:

$$
G_{c}^{m}(t)=\frac{\phi_{1}(v t) G(t)}{M_{b}}
$$

Figure 18 compares measured and simulated responses using the continuous force model with parameters (force, velocity, etc) as measured for the exemplary test subject and trial. The difference between vibration response of Tekscan-BS and Tekscan-RS reflects the effects of the footbridge vibration on the walking force, since the rigid surface force measurement is unaffected by any vibration. A significant reduction in the vibration response is observed when the walking force measured on the bridge surface is used in the simulation, providing insight into S2HI. The difference between Tekscan-BS response and load cell-BS response simply indicates any inaccuracies in the Tekscan measurements. The slight difference between the 
This paper has been published under the following reference: Ahmadi, E., Caprani, C., Zivanovic, S. and Heidarpour, A. Assessment of Human-Structure Interaction on a Lively Lightweight GFRP Footbridge. Engineering Structures. Vol. 199. Nov 2019. DOI:

https://doi.org/10.1016/i.engstruct.2019.109687

load cell and Tekscan-BS vibration responses shows good reliability of the procedure proposed in section 3.3. The load cell-BS response is very close to the measured response. This suggests that the human body as a dynamic system (in contrast to a moving force) is not having much influence on the dynamic properties of the footbridge in this example (H2SI). This is believed to be due to the relatively light weight of the test subject ( $71 \mathrm{~kg}, 7.8 \%$ mass ratio), and it complements the finding that the effect of the structure on the imparted force was quite significant (S2HI).

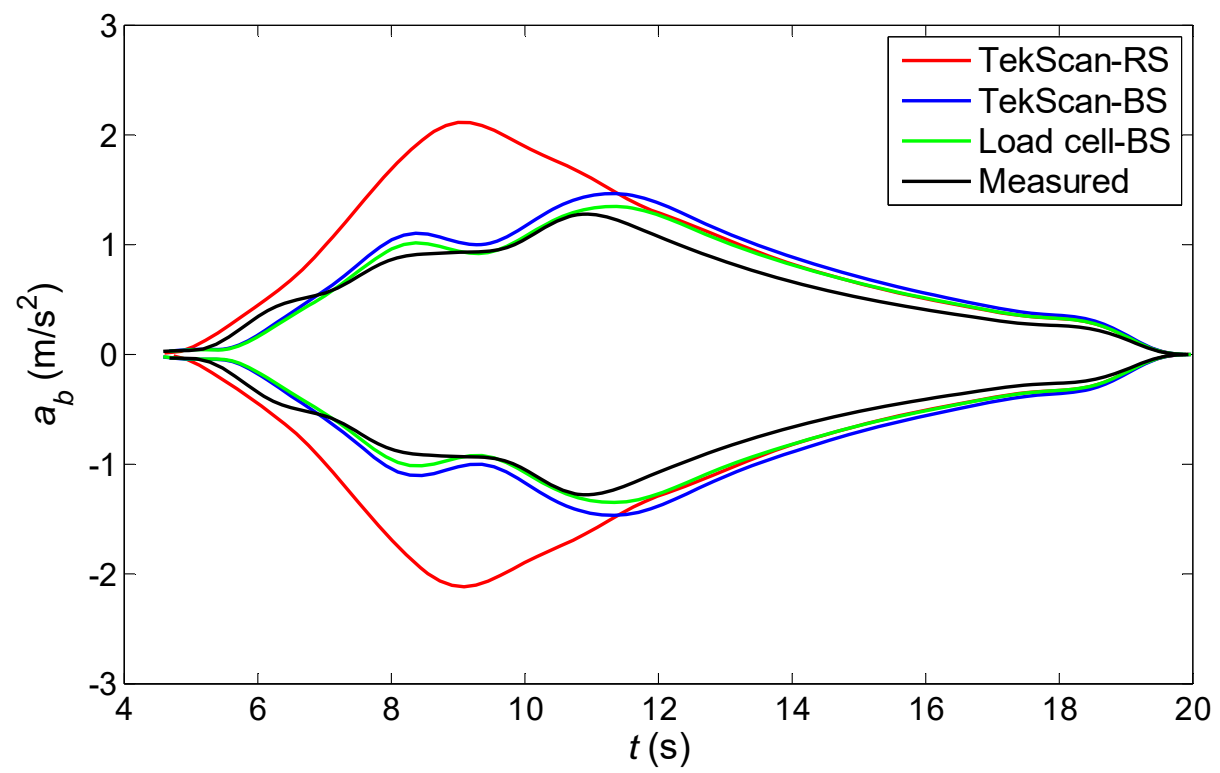

Figure 18. Acceleration envelopes of simulated and measured vibration responses for the exemplary test subject using continuous moving force model.

\subsection{Continuous versus discrete footfall moving force analysis}

Although the continuous moving force model is frequently used for vibration response estimation, applying the footstep forces at the location of the test subject's measured force resultant (Section 4.3) correctly represents the actual loading conditions. Thus, the discrete moving force model gives more faithful results, particularly for short-span footbridges. The discrete modal force is given by:

$$
G_{d}^{m}(t)=\frac{1}{M_{b}}\left[\sum_{i=1}^{n_{r}} \phi_{1}\left(x_{i}^{*}(t)\right) G_{r, i}(t)+\sum_{j=1}^{n_{l}} \phi_{1}\left(x_{j}^{*}(t)\right) G_{l, i}(t)\right]
$$


This paper has been published under the following reference: Ahmadi, E., Caprani, C., Zivanovic, S. and Heidarpour, A. Assessment of Human-Structure Interaction on a Lively Lightweight GFRP Footbridge. Engineering Structures. Vol. 199. Nov 2019. DOI:

https://doi.org/10.1016/i.engstruct.2019.109687

where $G_{r, i}$ and $G_{l, i}$ are the $i$ th right and the $j$ th left GRFs; $n_{r}$ and $n_{l}$ are the number of right and left footsteps, and the footstep location at time $t$ is:

$$
x_{k}^{*}(t)=H\left[t-\tau_{k}\right]-H\left[t-\left(\tau_{k}+\Delta \tau_{k}\right)\right]
$$

where $H[\cdot]$ is the Heaviside step function, $\tau_{k}$ is the start time of footstep $k$ lasting duration $\Delta \tau_{k}$. The load cells directly give the total walking force, not individual footstep forces. Hence the Tekscan measurements (corrected for error as described earlier) are used for the footstep GRFs in the discrete moving force model.

Figure 19a shows the simulated vibration response for both continuous and discrete force models for the exemplary test subject and Tekscan-measured bridge surface walking force. The vibration response for the discrete force model is slightly less than for the continuous force model. Expanding to all trials, and treating the discrete force model as the benchmark, the relative error is defined by:

$$
\varepsilon_{R}=\frac{R_{B S}^{d}-R_{B S}^{c}}{R_{B S}^{d}}
$$

where $R_{B S}^{d}$ and $R_{B S}^{c}$ are the maximum accelerations obtained using the bridge surface forces in the discrete and continuous force models, respectively. Figure 19b illustrates the histogram of the relative error, $\varepsilon_{R}$, for all trials. It shows that for all test subjects the discrete force model gives a smaller vibration response compared to the continuous force model, and this reduction is up to 0.2 for heavy test subjects. This demonstrates that continuous force modelling, mostly used in practice, is conservative, and thus, for vibration response simulations from BS and RS GRFs, Tekscan force results were used along with the discrete force model as it is more faithful to the actual loading condition (See Figure 1, parts (b) and (c)). 
(a)

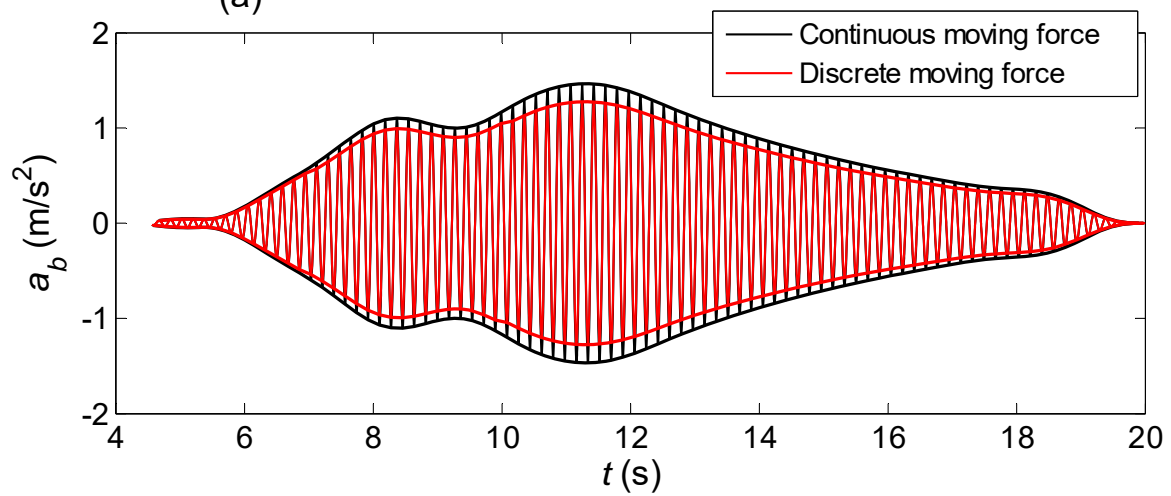

(b)

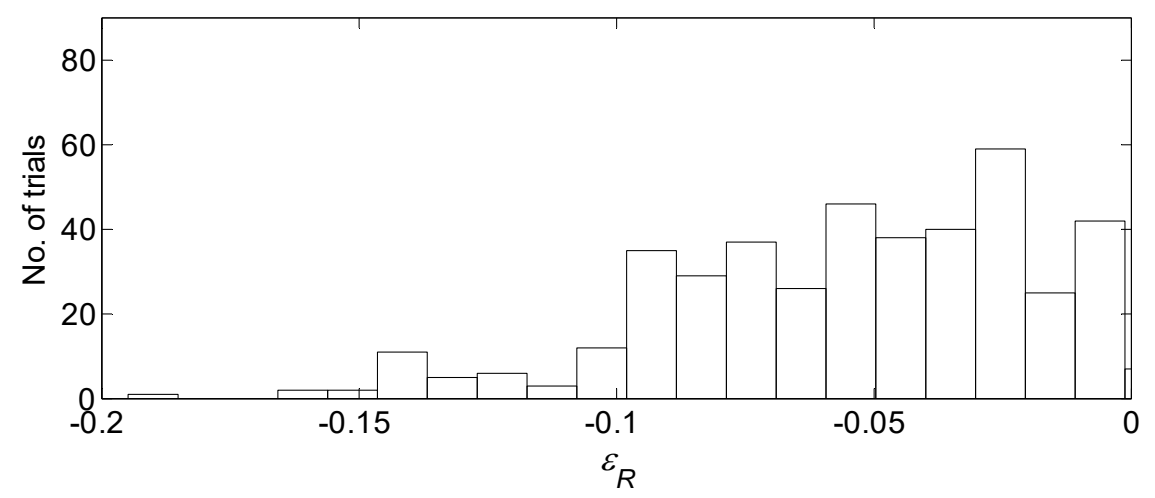

Figure 19. (a) Continuous versus discrete moving force models for the exemplary test subject, and (b) histogram of relative error between continuous and discrete moving force models for all trials.

\section{The Influence of Human-Structure Interaction}

This section explicitly addresses the three aims of this paper in light of the preceding results. Firstly, the current non-interacting force models are evaluated by comparing the simulated response with that measured (Aim 1). Secondly, the HSI forms are quantified for the lightweight bridge (Aim 2). Finally, the magnitudes of the HSI results for the lightweight bridge are compared with those for the heavier (Warwick) bridge to determine the relationship between HSI and subject mass-to-structure ratio (Aim 3).

\subsection{Aim 1: Accuracy of non-interacting force models}

As noted in Section 1.2, the vibration response prediction for footbridges is commonly recommended to be conducted using non-interacting force models, such as the continuous moving force model ([8], [9], [10], [11], [12], [13]). In these models a Fourier representation 
This paper has been published under the following reference: Ahmadi, E., Caprani, C., Zivanovic, S. and Heidarpour, A. Assessment of Human-Structure Interaction on a Lively Lightweight GFRP Footbridge. Engineering Structures. Vol. 199. Nov 2019. DOI: https://doi.org/10.1016/i.engstruct.2019.109687

of the walking force is often used (Caprani and Ahmadi [17]). Here, the DLFs proposed by Young [50], ISO 1037 [10], Brownjohn et al. [51], and Kerr [52] (shown in Table 2) along with zero phase angle are used to generate the walking force time histories. More similar models are available, such as Synpex and Setra, but the selected models are taken as representative of continuous moving force models.

Table 2. Dynamic load factors models used in the non-interacting continuous walking force models.

\begin{tabular}{lllll}
\hline$k$ & Young [50] & ISO 10137[10] & Brownjohn et al. [51] & Kerr [52] \\
\hline 1 & $0.41\left(f_{p}-0.95\right)<0.56$ & $0.37\left(f_{p}-1.0\right)$ & $0.37 f_{p}-0.42$ & $-0.26 f_{p}^{3}+1.32 f_{p}^{2}-1.76 f_{p}+0.76$ \\
2 & $0.069+0.0056 f_{p}$ & 0.1 & 0.053 & 0.07 \\
3 & $0.033+0.0064 f_{p}$ & 0.06 & 0.042 & 0.05 \\
4 & $0.013+0.0065 f_{p}$ & 0.06 & 0.041 & 0.05 \\
5 & - & 0.06 & 0.027 & - \\
6 & - & - & 0.018 & - \\
\hline
\end{tabular}

Figures $20 \mathrm{a}$ and $20 \mathrm{~b}$ compare the maximum acceleration response of measured signals with those from the non-interacting force models (using the DLFs in Table 2) for both the Monash (light) and Warwick (heavy) bridges. The models underestimate the vibration response for nonresonant walking for almost all trials. However, they highly overestimate the response for resonant walking for all trials. The overestimation is highest for ISO 10137 [10] force model, particularly for the heaviest test subject on the lightweight bridge. Young's force model [50] leads to a higher overestimation for the heavy bridge. The considerable difference between the non-interacting force models and the measured responses surely (at least partly) originates from ignoring human effects on dynamic properties of the human-structure system (H2SI) [24]. Furthermore, the DLFs in the models have been derived from measurements on treadmills or force plates situated on rigid surfaces whereas vibration can cause a significant drop in walking force (S2HI) [21], [24], [22]. Figure 20c shows the mean relative error between the simulated maximum acceleration responses and measurements for both footbridges for resonant walking. The force models have larger errors for the lightweight footbridge, up to five times the actual response. Further, higher overestimation of the force models for the lightweight bridge 
This paper has been published under the following reference: Ahmadi, E., Caprani, C., Zivanovic, S. and Heidarpour, A. Assessment of Human-Structure Interaction on a Lively Lightweight GFRP Footbridge. Engineering Structures. Vol. 199. Nov 2019. DOI:

https://doi.org/10.1016/i.engstruct.2019.109687

compared to the heavy bridge (see Figure 20c) implies a greater influence of HSI in the

lightweight bridge. These results are consistent with those in [7] where the current load models

estimate the vibration response well for the non-resonant cases, and an overestimation of the vibrations responses were reported for the resonant cases.

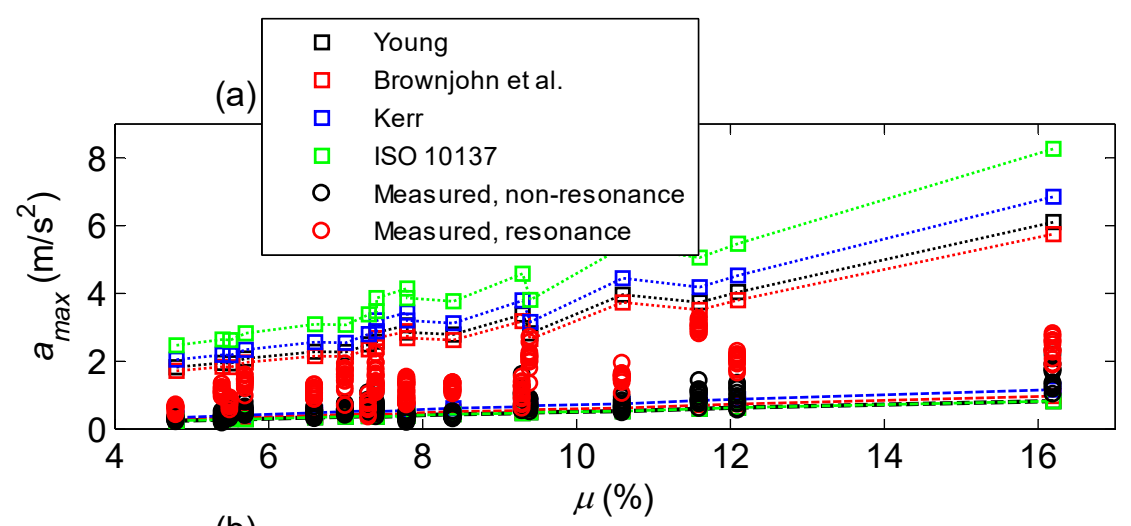

(b)

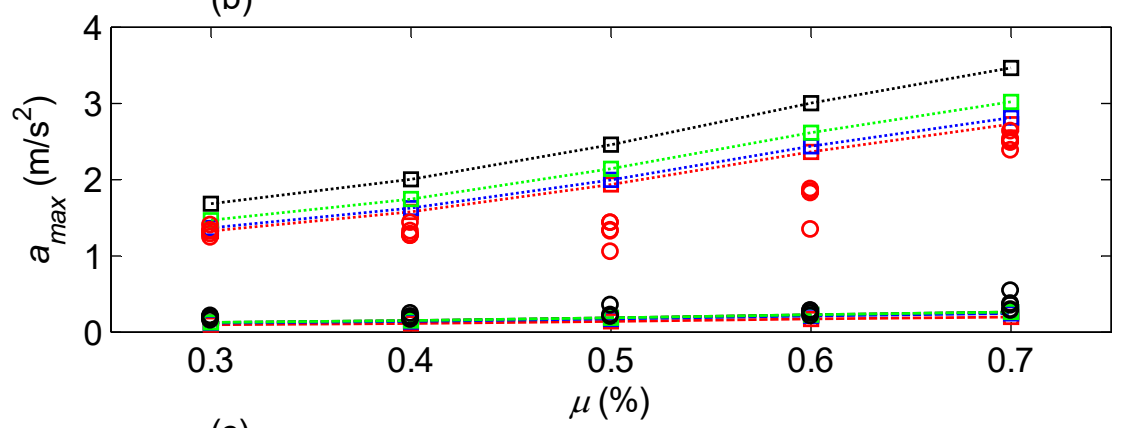

(c)

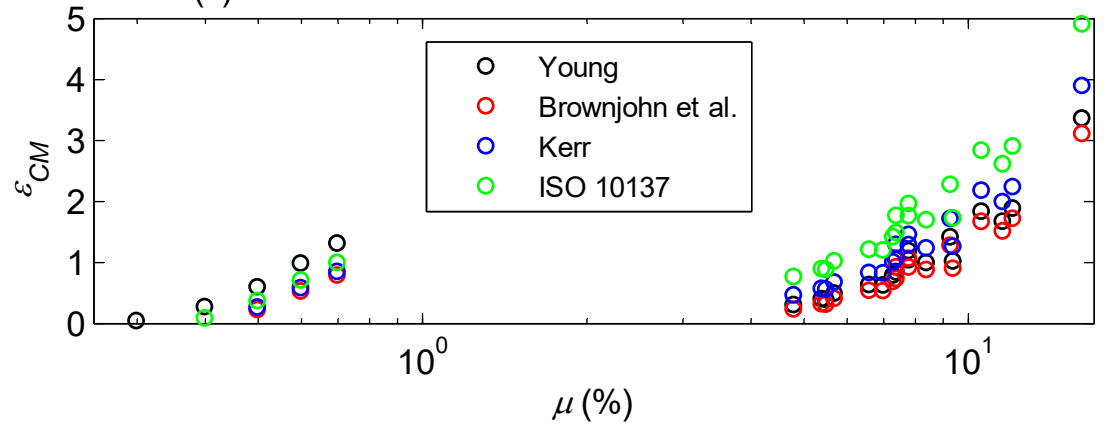

Figure 20. Maximum acceleration response from the considered moving force models and walking experiments (solid and dashed lines indicate resonance and non-resonance cases respectively): (a) lightweight Monash GFRP

footbridge, (b) heavy Warwick steel-concrete composite bridge, and; (c) model error (overestimation) for different bridge-to-mass ratios for a range of test subjects.

\subsection{Aim 2: Significance of human-structure interaction}

To quantify the effect of HSI on the response of the Monash footbridge, the relative difference between the mean vibration responses obtained from the bridge and rigid surface walking 
This paper has been published under the following reference: Ahmadi, E., Caprani, C., Zivanovic, S. and Heidarpour, A. Assessment of Human-Structure Interaction on a Lively Lightweight GFRP Footbridge. Engineering Structures. Vol. 199. Nov 2019. DOI:

https://doi.org/10.1016/i.engstruct.2019.109687

forces (see Figure 1) is used. Table 3 summarizes the S2HI and H2SI effects separately, and their combined effect using, respectively:

$$
\begin{gathered}
\Delta_{\mathrm{S} 2 \mathrm{HI}}=\left(\bar{R}_{R S}-\bar{R}_{B S}\right) / \bar{R}_{M} \\
\Delta_{\mathrm{H} 2 \mathrm{SI}}=\left(\bar{R}_{B S}-\bar{R}_{M}\right) / \bar{R}_{M} \\
\Delta_{\mathrm{HSI}}=\Delta_{\mathrm{S} 2 \mathrm{HI}}+\Delta_{\mathrm{H} 2 \mathrm{SI}}
\end{gathered}
$$

The higher drop in vibration response at resonant walking for all test subjects demonstrates a significant influence of S2HI on the vibration response. This drop is pronounced for the heaviest test subject, $\mu=16.2 \%$. The reduction in response due to H2SI is significantly lower than that of S2HI. This shows a comparatively stronger influence of S2HI. The lower effects of H2SI even for heavy test subjects could arise from the short contact time of the test subject with the bridge and short duration of the crossing [53]. It should be noted that the error of the footbridge numerical model involved in the simulations was up to $\pm 10 \%$ (section 3.1 ). This error is often much less than the differences $\left(\Delta_{\mathrm{H} 2 \mathrm{SI}}\right)$ presented in Table 3 for resonant cases, and thus the numerical model error cannot obscure meaningful conclusions on H2SI. For S2HI, since the same model was used for both rigid and bridge surface simulations, the vibration response difference can only be due to S2HI.

\subsection{Aim 3: Influence of mass ratio on HSI}

To determine influence of mass ratio on HSI, the results from the lightweight (Monash) bridge are compared to the heavy (Warwick) bridge. To have a correct and meaningful comparison, it is important to show that both bridges exhibit similar levels of liveliness since HSI is dependent on the bridge vibration level ([24], [22]). This is achieved by comparing the response factors for both bridges, which are taken as the ratios of complaint to perception thresholds [21]. For the Warwick Bridge, a previous study found that these response factors vary between 1.5-2.6 depending on pacing frequency, with a mean about 2.0 [21]. A similar study of vibration perception is therefore conducted for the Monash Bridge. 
This paper has been published under the following reference: Ahmadi, E., Caprani, C., Zivanovic, S. and Heidarpour, A. Assessment of Human-Structure Interaction on a Lively Lightweight GFRP Footbridge. Engineering Structures. Vol. 199. Nov 2019. DOI: https://doi.org/10.1016/i.engstruct.2019.109687

Table 3. Relative and combined influence of HSI types (see equations (20), (21), and (22)).

\begin{tabular}{ccccccc} 
& \multicolumn{3}{c}{ Non-resonant } & & \multicolumn{3}{c}{ Resonant } \\
\cline { 2 - 7 }$\mu(\%)$ & $\Delta_{\mathrm{S} 2 \mathrm{HI}}$ & $\Delta_{\mathrm{H} 2 \mathrm{SI}}$ & $\Delta_{\mathrm{HSI}}$ & $\Delta_{\mathrm{S} 2 \mathrm{HI}}$ & $\Delta_{\mathrm{H} 2 \mathrm{SI}}$ & $\Delta_{\mathrm{HSI}}$ \\
\hline 4.8 & 0.03 & 0.04 & 0.07 & 0.12 & 0.22 & 0.34 \\
5.4 & 0.24 & 0.03 & 0.27 & 0.54 & 0.17 & 0.71 \\
5.5 & 0.26 & 0.16 & 0.42 & 0.43 & 0.24 & 0.67 \\
5.7 & 0.35 & 0.06 & 0.41 & 0.60 & 0.27 & 0.87 \\
6.6 & 0.02 & 0.07 & 0.09 & 0.22 & 0.15 & 0.37 \\
7.0 & 0.18 & 0.11 & 0.29 & 0.32 & 0.18 & 0.50 \\
7.3 & 0.16 & 0.06 & 0.22 & 0.38 & 0.42 & 0.80 \\
7.4 & 0.30 & 0.12 & 0.42 & 0.69 & 0.48 & 1.17 \\
7.4 & 0.19 & 0.11 & 0.30 & 0.50 & 0.56 & 1.06 \\
7.8 & 0.24 & 0.03 & 0.27 & 0.44 & 0.14 & 0.58 \\
7.8 & 0.22 & 0.03 & 0.25 & 0.60 & 0.22 & 0.82 \\
8.4 & 0.31 & 0.13 & 0.44 & 0.58 & 0.32 & 0.90 \\
9.3 & 0.42 & 0.02 & 0.44 & 0.60 & 0.23 & 0.83 \\
9.4 & 0.17 & 0.10 & 0.27 & 0.75 & 0.12 & 0.87 \\
10.6 & 0.39 & 0.09 & 0.48 & 0.68 & 0.19 & 0.87 \\
11.6 & 0.39 & 0.08 & 0.47 & 0.67 & 0.16 & 0.83 \\
12.1 & 0.41 & 0.10 & 0.51 & 0.85 & 0.10 & 0.95 \\
16.2 & 0.64 & 0.11 & 0.75 & 2.95 & 0.62 & 3.57 \\
\hline & & & & & &
\end{tabular}

After each walking trial on the Monash Bridge, the test subjects were asked to subjectively categorize their perception of the vibration into one of following classes: no perception of vibration (CL1), acceptable vibration and no effect on walking style (CL2), acceptable vibration and occasional effect on walking style (CL3), and strong and uncomfortable vibration and frequent effect on walking style (CL4). These class are the same as those used in Setra [12] and similar to those in Dang \& Živanović [21]. To understand the relationship between the footbridge vibration response and perception classes, the maximum acceleration response of each acceleration signal, $a_{\max }$, against the actual pacing frequencies are presented in Figure 21 for different perception classes at vibration frequency of $5.6 \mathrm{~Hz}$. The red vertical dashed lines 
This paper has been published under the following reference: Ahmadi, E., Caprani, C., Zivanovic, S. and Heidarpour, A. Assessment of Human-Structure Interaction on a Lively Lightweight GFRP Footbridge. Engineering Structures. Vol. 199. Nov 2019. DOI:

https://doi.org/10.1016/i.engstruct.2019.109687

show the resonant range of the footbridge [22]. Interestingly, Figure 21 is quite similar to Warwick Bridge results [21] if we make two regions for pacing frequencies up to $1.91 \mathrm{~Hz}$ (upper limit of resonant range): (1) non-resonant zone, $f_{p}<1.83 \mathrm{~Hz}$ (lower limit of resonant range), and (2) resonant zone, $1.83<f_{p}<1.91 \mathrm{~Hz}$ ). Despite vibration frequency being quite different, the perception levels are similar for both Monash and Warwick bridges. Typically, as is expected, the resonant vibrations result in a higher perception of vibration than the nonresonant vibrations. However, in some cases, test subjects' sensitivity to vibration at nonresonant walking is also significant.

The mean maximum accelerations of the CL1 and CL2 perceptions are taken as the vibration perception threshold [21]; $0.98 \mathrm{~m} / \mathrm{s}^{2}$ and $0.45 \mathrm{~m} / \mathrm{s}^{2}$ for the resonant and the non-resonant cases (see Figure 21). The mean maximum accelerations for CL3 and CL4 are regarded as a complaint threshold [21]; $1.61 \mathrm{~m} / \mathrm{s}^{2}$ and $0.81 \mathrm{~m} / \mathrm{s}^{2}$ for the resonant and the non-resonant cases (see Figure 21). Thus, the response factors for the Monash Bridge are 1.64 and 1.80 for the resonant and the non-resonant cases respectively. A response factor of 2-4 is recommended for low probability of adverse occupant experiences during daytime vibration exposure in residential environments (Concrete Centre 2007 [54], ISO [10]). The results of this study indicate a response factor of approximately 2 is appropriate for walking. Interestingly, this finding is similar to those from the Warwick Bridge (1.5-2.6) [21]. Therefore, it can be concluded that the lightweight Monash and heavyweight Warwick Bridges are of similar liveliness. As such, a comparison of the level of HSI for each bridge at their resonance is more likely to do with the structure-to-human mass ratio, than to do with conscious vibration perception. 
This paper has been published under the following reference: Ahmadi, E., Caprani, C., Zivanovic, S. and Heidarpour, A. Assessment of Human-Structure Interaction on a Lively Lightweight GFRP Footbridge. Engineering Structures. Vol. 199. Nov 2019. DOI: https://doi.org/10.1016/i.engstruct.2019.109687

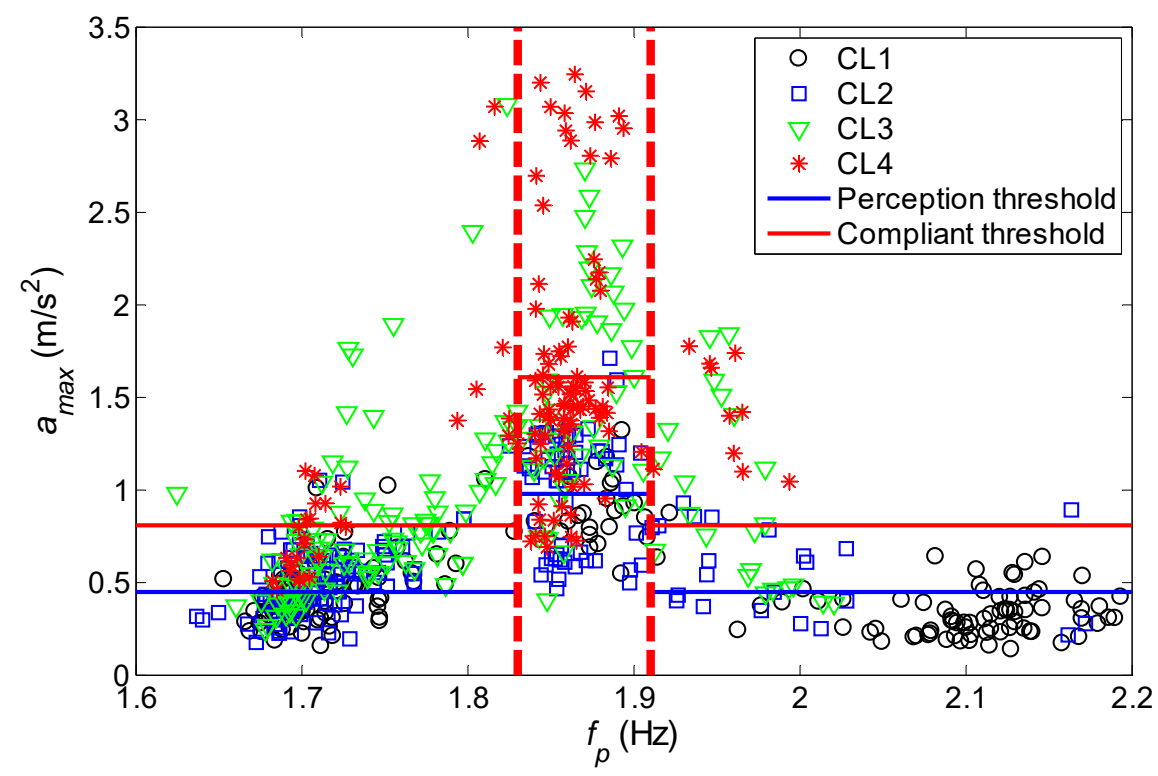

Figure 21. Maximum acceleration response versus pacing frequencies for test subjects' perception classifications (vertical red dashed lines show resonance range) at vibration frequency of $5.6 \mathrm{~Hz}$.

As HSI has the highest effect for the resonant walking (see Table 3 and Ahmadi et al. [24]),

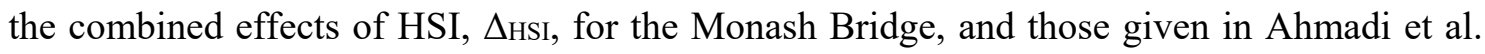
[24] for the Warwick Bridge, are compared. Figure 22 shows the magnitudes of HSI against test subject-to-structure mass ratio for resonant walking. It is quite evident that the magnitude of HSI is correlated with the mass ratio, and the Monash Bridge (light) gives HSI magnitudes far higher than the Warwick Bridge (heavy). Indeed, even for the same test subject on both bridges (as highlighted in the Figure 22 by green filled circle and square), it is clear that the magnitude of HSI is strongly influenced $(0.38$ vs 0.78$)$. It is therefore apparent that future models that account for HSI should also consider the subject-to-structure mass ratio. 


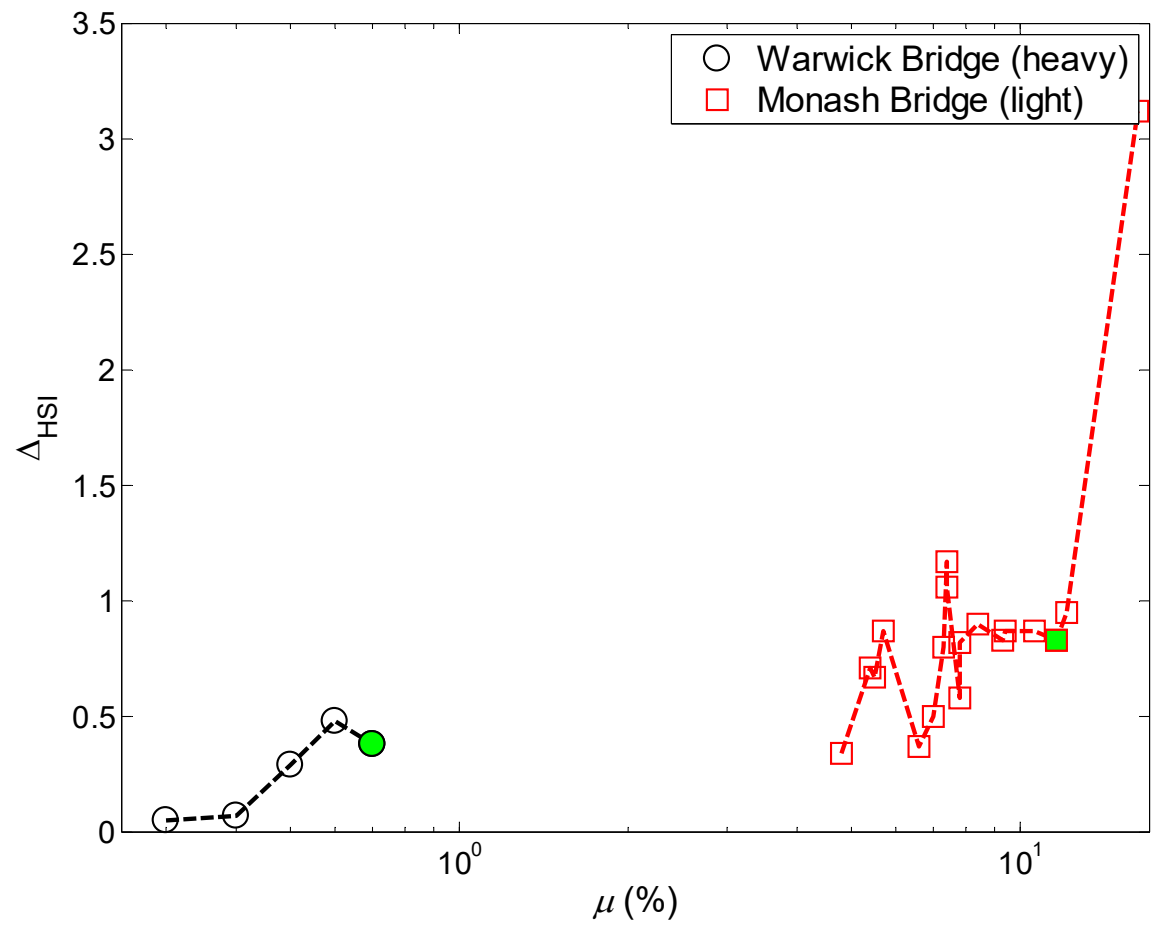

Figure 22. Total HSI effect for resonant walking on both the Warwick (heavy) and Monash (light) Bridges. The two results for the common test subject on both bridges are indicated by a filled-in circle.

\section{Conclusions}

This paper investigates the contribution of human-structure interaction (HSI) to vibration response of a lively lightweight GFRP footbridge at the Monash University; it also compares some aspects of HSI with previously published results from the heavier Warwick Bridge with a mass per unit length about eight times larger than for the Monash bridge. An extensive set of walking trial tests involving 18 walkers was performed. During each trial, the footfall force was measured on the vibrating footbridge surface and the rigid surface along with the footbridge vibration response. The force measurements errors and the footbridge numerical model error were quantified. Moving force models were used to simulate vibration responses from the walking forces measured on both rigid and bridge surfaces. Three aims of the research have been addressed. 
This paper has been published under the following reference: Ahmadi, E., Caprani, C., Zivanovic, S. and Heidarpour, A. Assessment of Human-Structure Interaction on a Lively Lightweight GFRP Footbridge. Engineering Structures. Vol. 199. Nov 2019. DOI: https://doi.org/10.1016/i.engstruct.2019.109687

Firstly, it is found that non-interacting force models from the literature highly overestimate the vibration response of both Monash and Warwick footbridges at resonant walking. This overestimation is around three times higher for the lightweight GFRP Monash bridge suggesting that consideration of human-structure interaction seems indispensable for the design and assessment of lightweight structures.

Secondly, quantification of human-structure interaction was carried out for the lightweight bridge using an experimental-numerical programme. The structure's influence on human walking (S2HI) was found to be up to around nine times higher than the human's influence on the structure (H2SI). This effect can be included in moving force models by reducing the DLF of the walking harmonic closest to an integer multiple of the footbridge natural frequency of interest.

Thirdly, using analysis of walking test subject perceptions, it is concluded that the response factor for the lightweight footbridge is similar to that of the heavier bridge and the lower limit suggested for residential structures and non-walking postures. This indicates that both bridges have similar liveliness under human walking. Consequently, the comparison of HSI for both bridges shows the importance of human-to-structure mass ratio. It is found that HSI is far more significant in the lightweight footbridge due to this higher mass ratio. Consequently, consideration in the vibration serviceability assessment of lightweight structures should be given to HSI. Furthermore, for system identification in the presence of pedestrians and the design of vibration control systems, inclusion of HSI could be significant in achieving desired results. 
This paper has been published under the following reference: Ahmadi, E., Caprani, C., Zivanovic, S. and Heidarpour, A. Assessment of Human-Structure Interaction on a Lively Lightweight GFRP Footbridge. Engineering Structures. Vol. 199. Nov 2019. DOI:

https://doi.org/10.1016/i.engstruct.2019.109687

\section{Acknowledgement}

This work was funded by a Monash-Warwick Alliance Seed Grant and a Monash Graduate Scholarship (MGS). The third author also acknowledges support received by the UK Engineering and Physical Sciences Research Council [grant number EP/M021505/1: Characterising Dynamic Performance of Fibre Reinforced Polymer Structures for Resilience and Sustainability].

\section{References}

[1] Zivanovic S, Wei X, Russell J, Mottram JT. Vibration Performance of Two FRP Footbridge Structures in the United Kingdom. Footbridge 2017 Berlin - Tell A Story: Conference Proceedings 6-892017 TU-Berlin 2017. doi:10.24904/footbridge2017.09384.

[2] Živanovi'c S, Feltrin G, Mottram JT, Brownjohn JMW. Vibration Performance of Bridges Made of Fibre Reinforced Polymer. IMAC-XXXII, Orlando, Florida, USA, 3 6 February., 2014, p. 155-62. doi:10.1007/978-1-4419-9831-6.

[3] He W, Xie W. Characterization of stationary and walking people on vertical dynamic properties of a lively lightweight bridge. Structural Control and Health Monitoring 2018;25:e2123. doi:10.1002/stc.2123.

[4] Shahabpoor E, Pavic A, Racic V. Interaction between walking humans and structures in vertical direction: a literature review. Shock and Vibration 2016;2016:12-7. doi:10.1155/2016/3430285.

[5] Dey P, Narasimhan S, Walbridge S. Calibrating Pedestrian-Bridge Standards for Vibration Serviceability. Journal of Bridge Engineering 2018;23:1-17. doi:10.1061/(ASCE)BE.1943-5592.0001270.

[6] Dey P, Narasimhan S, Walbridge S. Evaluation of design guidelines for the serviceability assessment of aluminum pedestrian bridges. Journal of Bridge Engineering 2017;22:1-15. doi:10.1061/(ASCE)BE.1943-5592.0000983.

[7] Dey P, Sychterz A, Narasimhan S, Walbridge S. Performance of Pedestrian-Load Models through Experimental Studies on Lightweight Aluminum Bridges. Journal of Bridge Engineering 2016;21:C4015005. doi:10.1061/(ASCE)BE.1943-5592.0000824.

[8] OHBDC, Ontario Highway Bridge Design Code, Highway Engineering Division, Ministry of Transportation and Communication, Ontario, Canada. 1983.

[9] BSI (British Standards Institution). U.K. national annex to Euro- code 1: Actions on structures_-Part 2: Traffic loads on bridges. EN 1991-2:2003, London. 2008.

[10] ISO 10137 - Bases for design of structures - Serviceability of buildings and walkways against vibrations. 1992.

[11] Eurocode 5, Design of Timber Structures-Part 2: Bridges, ENV 1995-2: 1997, 
This paper has been published under the following reference: Ahmadi, E., Caprani, C., Zivanovic, S. and Heidarpour, A. Assessment of Human-Structure Interaction on a Lively Lightweight GFRP Footbridge. Engineering Structures. Vol. 199. Nov 2019. DOI:

https://doi.org/10.1016/i.engstruct.2019.109687

European Committee for Standardization 1997.

[12] Sétra, Guide methodologique passerelles pietonnes (Technical guide Footbridges: assessment of vibrational behaviour of footbridges under pedestrian loading). 2006.

[13] Design of footbridges - HIVOSS (Human Induced Vibrations of Steel Structures). 2009.

[14] Rainer JH, Pernica G, Allen DE. Dynamic loading and response of footbridges. Canadian Journal of Civil Engineering 1988;15:66-71. doi:10.1139/188-007.

[15] Yao S, Wright JR, Pavic A, Reynolds P. Forces generated when bouncing or jumping on a flexible structure. ISMA, vol. 2, Leuven, Belgium: 2002, p. 563-72.

[16] Wheeler JE. Prediction and Control of Pedestrian-Induced Vibration in Footbridges. ASCE Journal of the Structural Division 1982;108:2045-65.

[17] Caprani CC, Ahmadi E. Formulation of human-structure system models for vertical vibration. Journal of Sound and Vibration 2016. doi:http://dx.doi.org/10.1016/j.jsv.2016.05.015.

[18] Ohlsson SV. Floor vibrations and human discomfort, PhD Thesis, Go“ teborg, Sweden. Chalmers University of Technology, 1982.

[19] Baumann K, Bachmann H. Durch menschen verursachte dynamische lasten und deren auswirkungen auf balkentragwerke, Swiss Federal Institute of Technology (ETH), Z"urich, Switzerland. 1988.

[20] Pimentel RL. Vibrational performance of pedestrian bridges due to human-induced loads. University of Sheffield, Sheffield, UK, 1997.

[21] Dang HV, Živanovic S. Influence of low-frequency vertical vibration on walking locomotion. Journal of Structural Engineering 2016;142:1-12. doi:10.1061/(ASCE)ST.1943-541X.0001599.

[22] Ahmadi E, Caprani C, Živanović S, Heirdapour A. Vertical ground reaction forces on rigid and vibrating surfaces for vibration serviceability assessment of structures.

Engineering Structures 2018;172:723-38. doi:https://doi.org/10.1016/j.engstruct.2018.06.059.

[23] Ahmadi E, Caprani C, Živanović S, Evans N, Heidarpour A. A framework for quantification of human-structure interaction in vertical direction. Journal of Sound and Vibration 2018;432:351-72. doi:10.1016/j.jsv.2018.06.054.

[24] Ahmadi E, Živanović S, Caprani C, Evans N, Heirdapour A. A framework for quantification of human-structure interaction in vertical direction. Journal of Sound and Vibration 2018;432. doi:10.1016/j.jsv.2018.06.054.

[25] Busca G, Cappellini A, Manzoni S, Tarabini M, Vanali M. Quantification of changes in modal parameters due to the presence of passive people on a slender structure. Journal of Sound and Vibration 2014;333:5641-52. doi:10.1016/j.jsv.2014.06.003.

[26] Ahmadi E, Caprani CC, Heidarpour A. An equivalent moving force model for consideration of human-structure interaction. Applied Mathematical Modelling 2017;51:526-45. doi:10.1016/j.apm.2017.06.042.

[27] Willford M. Dynamic actions and reactions of pedestrians. Proceedings of the International Conference on the Design and Dynamic Behaviour of Footbridges, Paris, France: 2002, p. 66-73. 
This paper has been published under the following reference: Ahmadi, E., Caprani, C., Zivanovic, S. and Heidarpour, A. Assessment of Human-Structure Interaction on a Lively Lightweight GFRP Footbridge. Engineering Structures. Vol. 199. Nov 2019. DOI:

https://doi.org/10.1016/i.engstruct.2019.109687

[28] Živanović S, Diaz IM, Pavić A. Influence of walking and standing crowds on structural dynamic properties. the 27th IMAC Conference, Orlando, USA: 2009.

[29] Nimmen K Van, Maes K, Živanović S, Lombaert G, Roeck G De, Broeck P Van den. Identification and modelling of vertical human-structure interaction. Proceedings of the 33th International Modal Analysis Conference Series, Orlando: 2015.

[30] Živanović S, Pavić A, Ingólfsson ET. Modeling spatially unrestricted pedestrian traffic on footbridges. Journal of Structural Engineering 2010;136:1296-308.

doi:10.1061/(ASCE)ST.1943-541X.0000226.

[31] Caprani CC, Keogh J, Archbold P, Fanning P. Enhancement factors for the vertical response of footbridges subjected to stochastic crowd loading. Computers and Structures 2012;102-103:87-96. doi:10.1016/j.compstruc.2012.03.006.

[32] Kasperski M. Damping induced by pedestrians. the 9th International Conference on Structural Dynamics, EURODYN, Porto, Portugal: 2014, p. 1059-64.

[33] Bertec corporation, user manual, 2012. http://bertec.com.

[34] HBM corporation, user manual, 2017. https://www.hbm.com.

[35] Tekscan, Force Measurement and Tactile Sensors, 2017. https://www.tekscan.com.

[36] Forner Cordero A, Koopman HJFM, Van Der Helm FCT. Use of pressure insoles to calculate the complete ground reaction forces. Journal of Biomechanics 2004;37:142732. doi:10.1016/j.jbiomech.2003.12.016.

[37] Fong DTP, Chan YY, Hong Y, Yung PSH, Fung KY, Chan KM. Estimating the complete ground reaction forces with pressure insoles in walking. Journal of Biomechanics 2008;41:2597-601. doi:10.1016/j.jbiomech.2008.05.007.

[38] Chopra AK. Dynamics of structures : theory and applications to earthquake engineering. 3rd ed. Prentice Hall, New Jersey: Pearson Education; 2007. doi:10.1002/9781118599792.

[39] Humar JL. Dynamics of structures. 3rd ed. London: Taylor \& Francis; 2012.

[40] Chopra AK. Dynamics of Structures - Theory and Applications to Earthquake Engineering. Prentice Hall, New Jersey: 2007.

[41] Drewniak EI, Crisco JJ, Spenciner DB, Fleming BC. Accuracy of circular contact area measurements with thin-film pressure sensors. Journal of Biomechanics 2007;40:2569-72. doi:10.1016/j.jbiomech.2006.12.002.

[42] Den Hartog JP. Mechanical vibrations. 4th ed. New York: McGraw-Hill: 1956.

[43] Yalla SK, Kareem A. Beat phenomenon in combined structure-liquid damper systems. Engineering Structures 2001;23:622-30. doi:10.1016/S0141-0296(00)00085-7.

[44] Zhou GD, Yi TH. A summary review of correlations between temperatures and vibration properties of long-span bridges. Mathematical Problems in Engineering 2014;2014. doi:10.1155/2014/638209.

[45] Brownjohn JMW, Pavic A. Experimental methods for estimating modal mass in footbridges using human-induced dynamic excitation. Engineering Structures 2007;29:2833-43. doi:10.1016/j.engstruct.2007.01.025.

[46] Shih-Hsun Yin. Vibration assessment of a simply supported footbridge under discrete pedestrian loading. Chinese Institute of Engineers 2017;40:503-13. 
This paper has been published under the following reference: Ahmadi, E., Caprani, C., Zivanovic, S. and Heidarpour, A. Assessment of

Human-Structure Interaction on a Lively Lightweight GFRP Footbridge. Engineering Structures. Vol. 199. Nov 2019. DOI:

https://doi.org/10.1016/i.engstruct.2019.109687

doi:10.1080/02533839.2017.1347062.

[47] Li Q, Fan J, Nie J, Li Q, Chen Y. Crowd-induced random vibration of footbridge and vibration control using multiple tuned mass dampers. Journal of Sound and Vibration 2010;329:4068-92. doi:10.1016/j.jsv.2010.04.013.

[48] Blanchard J, Davies BL, Smith JW. Design criteria and analysis for dynamic loading of footbridges. Proceeding of a Symposium on Dynamic Behaviour of Bridges at the Transport and Road Research Laboratory, Crowthorne, Berkshire, England, 1977.

[49] Smith JW. Vibration of structures : applications in civil engineering design. London: Chapman and Hall; 1988.

[50] P. Young. Improved floor vibration prediction methodologies, ARUP vibration seminar. 2001.

[51] Brownjohn JM., Pavic A, Omenzetter P. A spectral density approach for modelling continuous vertical forces on pedestrian structures due to walking. Canadian Journal of Civil Engineering 2004;31:65-77. doi:10.1139/103-072.

[52] Kerr SC. Human Induced Loading on Staircases. 1998. doi:10.1016/S01410296(00)00020-1.

[53] Brownjohn JMW, Tao NF. Vibration excitation and control of a pedestrian walkway by individuals and crowds. Journal of Shock and Vibration 2005;12:333-47.

[54] Concrete Centre. A design guide for footfall induced vibration of structures. 2007. 